\title{
Optimal Long-Term Financial Contracting
}

\author{
Peter M. DeMarzo \\ Stanford University \\ Michael J. Fishman \\ Northwestern University
}

\begin{abstract}
We develop an agency model of financial contracting. We derive long-term debt, a line of credit, and equity as optimal securities, capturing the debt coupon and maturity; the interest rate and limits on the credit line; inside versus outside equity; dividend policy; and capital structure dynamics. The optimal debt-equity ratio is history dependent, but debt and credit line terms are independent of the amount financed and, in some cases, the severity of the agency problem. In our model, the agent can divert cash flows; we also consider settings in which the agent undertakes hidden effort, or can control cash flow risk. (JEL G30, G32, G35, D82, D86, D92)
\end{abstract}

We develop a model of long-term financial contracting and derive debt and equity as optimal securities. Our analysis captures the optimal coupon and maturity structure for long-term debt; the interest rate and credit available on a line of credit; debt versus (outside) equity financing; and dividend policy. The model has implications for how a firm's capital structure varies over time. The scenario we consider involves an agent who raises external capital to finance a business opportunity. Among investors' concerns in funding a business is that the agent might divert funds to himself, or consume other private benefits, at the expense of investors. Our analysis focuses on this agency problem.

Specifically, in the model, a risk-neutral agent seeks funding from riskneutral investors. The funding will finance a business that requires an investment in assets and generates risky cash flows over the next $T$ periods. The agent observes the realizations of these cash flows but investors do not. The agency problem is that the agent can underreport the cash flow, diverting the cash flow for his own private benefit. At any time during the life of the business, the business can be terminated. In the event of termination, the agent is left to pursue his best alternative and investors are free to make optimal use of the assets. The termination threat is the key to inducing the agent to share the cash flow with investors. A contract

We would like to thank Mark Garmaise, Denis Gromb, Bob McDonald, Maureen O'Hara, two reviewers, and seminar and conference participants for helpful comments. This article is based on research supported in part by the NBER and the National Science Foundation under grant No. 0452686. Address correspondence to Michael J. Fishman, Kellogg School of Management, Northwestern University, 2001 Sheridan Road, Evanston, IL 60208, or e-mail: m-fishman@kellogg.northwestern.edu. 
specifies payments between the agent and investors and it specifies the circumstances under which the project is terminated.

We fully characterize the optimal contract for the multiperiod case with uncertainty. After solving for the contract as an optimal mechanism, we demonstrate that it can be implemented by a combination of equity, longterm debt, and a line of credit - very simple, standard securities. Thus we have a theory of long-term debt and outside equity financing. The optimal capital structure is shown to be both forward looking and history dependent. That is, the capital structure depends on the distribution of the firm's cash flows (past and future) and the history of the firm's cash flow realizations. In addition, the terms of the firm's long-term debt and credit line are independent of the amount financed and, under certain circumstances, independent of the severity of the moral hazard problem.

The optimal long-term debt and credit line can be described as follows. In each period, the agent is required to pay a fixed charge, principal plus interest - this is the payment on the long-term debt. The credit line is characterized by an interest rate and a credit limit. Payments need not be made on the credit line except for interest payments once the credit limit is reached, and required payments if the credit limit is reduced. If a required debt or credit line payment is not made, the agent is in default, in which case there is some probability that the project is terminated (this probability is increasing in the extent of the default). The agent will make optimal use of the line of credit. If he cannot make a debt payment out of the business cash flow, he will draw on the line of credit. If needed, the agent continues to draw on the line of credit until it is exhausted. After that, if the agent cannot make a payment, he may be terminated. Though the agent could draw on the line of credit and simply pay the cash to himself, the increased interest expense and likelihood of default make it optimal for him not to do so. If the business cash flow exceeds the debt payment, then the agent uses the excess cash to pay down the credit line and after that pays out the remainder of the cash as a dividend. The equity shares of the investors and agent determine the split of this dividend.

The intuition for how these securities implement the optimal contract is as follows. In the model, the agent's private benefit of diverting funds equals $\lambda$ per dollar diverted, where $0<\lambda \leq 1$. Thus, to induce the agent to refrain from diverting cash flows, the agent's payoff from the contract must adjust at a rate of $\lambda$ per dollar of cash flow reported. The agent can be compensated either with cash paid immediately or through the promise of higher expected cash payments in the future. The choice between the two involves a tradeoff: the agent is impatient, and so prefers earlier consumption, but deferring the agent's compensation is more effective for providing incentives in the future.

With risk neutrality, the optimal resolution of this tradeoff is stark: If the agent's expected future compensation rises to a critical threshold, 
it is cheaper on the margin to compensate the agent with cash in the current period. Thus, if the firm does well, the optimal contract raises the agent's expected future compensation until the threshold is reached, and then pays the agent in cash. If the firm does poorly, the agent's expected future compensation is lowered until it falls below the minimum efficient level of compensation for the agent (based on the incentive constraints). The contract then randomizes between terminating and restarting with the agent's compensation set to the minimum efficient level.

This contract can be implemented with the capital structure described earlier. The agent holds equity in the firm, and so receives cash when dividends are paid. Because dividends are paid only after the firm has paid off its credit line, the balance on the credit line determines the agent's expected future payments. As the firm repays or draws down the credit line based on its current cash flows, the agent's expected future compensation increases or decreases appropriately. If the firm does poorly and the credit line is drawn to its limit, the firm defaults and either the contract is terminated, or the excess debt is forgiven and the firm is allowed to continue.

The long-term debt and line of credit play different roles in implementing the optimal contract. The long-term debt is effective for financing early consumption for the agent (if the agent is impatient relative to outside investors). If the agent is not impatient, the firm issues minimal longterm debt, with payments matching the firm's lowest possible cash flows. And once the credit line is repaid there is no further chance of default. The line of credit provides the firm with the efficient level of financial slack given that its cash flows are risky. If the business is riskless, no credit line is needed - with no cash flow risk, the fixed debt payments can simultaneously fund the up-front investment as well as fund the agent's early consumption (if desired).

The threat that induces the agent to pay investors is that the project can be terminated. Our modeling here covers a variety of situations. Termination could involve liquidating the assets, selling them piecemeal at market prices. In this case, termination involves an exogenous liquidation payoff that may vary over the life of the business. Alternatively, termination could involve the sale of the business as a going concern. Here the sale price, and hence the termination payoff are endogenous and depend on the remaining life of the business and on the wealth of potential buyers. For if a buyer must finance the purchase, the same problem reemerges - the price a buyer can pay is determined by the solution to the optimal contracting problem. For the agent, termination may result in his accepting his next best employment alternative. In this case, termination involves an exogenous agent payoff. Alternatively, termination could result in the agent borrowing to start a new business. Here the agent's termination payoff is endogenous and depends upon the financing terms he can obtain 
for the new business, which is again determined by the solution to the optimal contracting problem. After characterizing the optimal contract, we explore these and other interpretations of termination.

Debt financing is often seen as problematic because of asset-substitution (risk-shifting) problems. That is, equity holders may seek to make the firm riskier in order to transfer wealth from debt holders. In our analysis, even though the optimal contract involves debt, there is no asset-substitution problem. The agent, an equity holder, does not benefit from an increase in cash flow risk. In a given period, the agent's total payoff consists of a current cash payment plus a continuation payoff (the discounted value of the agent's expected future payments, accounting for the possibility of termination). While the agent's current cash payment is convex in the business cash flow, his total payoff (current cash plus continuation) is linear in the business cash flow. With a linear payoff, an increase in risk via a mean-preserving spread does not benefit the agent. As will be seen, this linear payoff follows from the agent's incentive-compatibility constraint.

We also extend our model to consider contracting with hidden agent effort. Under our contract, the agent's equity share determines his incentives to provide effort. We show that for several standard settings our contract, with an equity share for the agent that is sufficient to induce high effort in a static setting, is the optimal principal-agent contract with hidden effort.

Our analysis covers both the case in which the agent and investors can commit to a contract and the case in which contracts can be renegotiated. With the possibility of renegotiation, the contract must be Pareto optimal throughout its life - otherwise the agent and investors would renegotiate. Of course, the possibility of renegotiation effectively entails more constraints on the contracting problem and hence leads to worse outcomes.

A number of other analyses also examine how financial contracts can be designed to induce agents to make payments to investors rather than diverting the cash flow to themselves. Diamond (1984) and Bolton and Scharfstein (1990) analyze one-period models in which a risky cash flow is observed only by the agent and can be diverted by the agent. They show that the optimal contract is debt, and if the agent defaults he faces a cost that can be interpreted as forfeiting collateral or not being refinanced in the future. Gromb (1999) considers a multiperiod version of this model in which the threat facing the agent is that future funding will be withheld. Gromb provides a partial characterization of the optimal contract, showing that it may be optimal to provide the agent with slack in the sense that it may take several low payments before his funding is cut off. Gromb does not address security design issues. Quadrini (2004); Clementi and Hopenhayn (2006), and DeMarzo and Fishman (2007) also examine multiperiod versions of this model and allow for the determination of the 
scale of the firm. These articles focus on firm investment and growth. Our focus here is on security design. We fully characterize the optimal financial contract for the multiperiod case with uncertainty.

In other related analyses, Allen (1983) and Hart (1995) examine multiperiod contracting models in which the agent finances a riskless business. Bulow and Rogoff (1989) and Atkeson (1991) consider multiperiod models of sovereign debt. Hart and Moore (1998) and Harris and Raviv (1995) examine two-period financial contracting models with risky cash flows (all uncertainty is resolved immediately after the agent and investors sign a contract). Hart-Moore and Harris-Raviv assume that while cash flows are observable to both the agent and investors, they still may not be contractible. In these analyses, the optimal contract is implemented with debt. Fluck (1998) and Myers (2000) also examine models in which cash flows are observable but not contractible, and in their settings, the optimal contract is implemented by giving the investors equity. In contrast, we assume that the (risky) cash flows are observable only by the agent and hence are not directly contractible. In our analysis, the optimal contract is implemented by a combination of outside equity and debt. In all of these analyses, some threat induces the agent to share the cash flow with investors. These threats include: the seizure of assets, withholding future funding, interrupting trade, and so on. Our model is general enough to cover all of these possibilities. Moreover, since cash flows are both risky and unobservable by investors, the threat is invoked in equilibrium in our model.

An extensive literature studies optimal contracts for risk sharing with privately observed cash flows. To mention a few, Green (1987) examines optimal contracts in an infinite-horizon model, in which each agent's income has an independent and identically distributed (i.i.d.) binary outcome in each period. Townsend (1979) and Mookherjee and Png (1989) analyze one-period models in which a costly audit can reveal an agent's income. Wang (2005) combines these ideas, analyzing a version of Green's model with deterministic auditing (a low income report is certainly audited and a high income report is not). Our analysis does not incorporate risk sharing or audits. Both would be important extensions.

Finally, DeMarzo and Sannikov (2006) consider a continuous-time, infinite horizon version of the discrete time model analyzed here. In their setting, the optimal contract can be further simplified (e.g., termination is not randomized) and compensating balances (i.e., holding cash while borrowing at a higher rate) emerge as part of the optimal contract. The optimal contract and security prices can be solved as a standard differential equation, allowing for an analytic determination of optimal capital structure and comparative statics. Biais et al. (2007) derive the continuous-time limit of a stationary version of our model with binomial cash flows. They consider an alternative implementation of the optimal 
contract in which the firm uses cash reserves in place of the credit line and they derive additional asset pricing implications.

Section 1 presents the model. Section 2 solves for the optimal contract, and Section 3 shows how the optimal contract can be implemented with a combination of long-term debt, a line of credit, and equity. Section 4 shows how by varying the specification of payoffs in the event of termination, we can accommodate a variety of situations and nest some prior analyses. Section 5 discusses the asset-substitution problem and the moral hazard problem involving costly hidden agent effort. Section 6 has concluding remarks. Proofs are provided in the Appendix.

\section{The Model}

There are an agent and investors. Investors are risk neutral, have unlimited capital, and value a cash flow stream $\left\{c_{t}\right\}$ as $\sum_{t} e^{-r t} E\left[c_{t}\right]$, where $r$ is the riskless interest rate. The agent is also risk neutral, has limited capital, and values a cash-flow stream $\left\{c_{t}\right\}$ as $\sum_{t} e^{-\gamma t} E\left[c_{t}\right]$, where $\gamma \geq r$ is the subjective discount rate.

The agent has a risky project that requires an initial investment in assets of $I$, in period $t=0$. The agent privately observes his initial wealth $Y_{0} \geq 0$. If $I>Y_{0}$, the agent must raise external funds to finance the project. Alternatively, even if $Y_{0} \geq I$, if $\gamma>r$ the agent would like to raise external funds for consumption purposes. ${ }^{1}$

\subsection{The Project}

If funded, the project's cash flow in period $t$ is given by the random variable $Y_{t}$. The cash flows $\left\{Y_{t}\right\}$ are jointly independent and for $s<t, E_{s}\left[Y_{t}\right]=E\left[Y_{t}\right]=\mu_{t}$; that is, there is no learning about future cash flows. Denote the minimum element of the support of $Y_{t}$ by $Y_{t}^{0}{ }^{2}{ }^{2}$ The minimal cash flow $Y_{t}^{0}$ is publicly observable and collectible by investors. ${ }^{3}$ The excess cash flow realizations $Y_{t}-Y_{t}^{0}$, however, are privately observed by the agent. The moral hazard problem is that the agent might conceal a cash flow and then divert it to himself for personal consumption. We assume that for each dollar that the agent conceals and diverts from the firm, the agent can consume $\lambda$, where $\lambda \in[0,1]$. That is, $1-\lambda$ represents the cost of diverting firm funds for private consumption (for example, by consuming inefficient perks). A common assumption is that diversion is

\footnotetext{
${ }^{1}$ We do not consider the case $\gamma<r$. In this case investors would like to borrow from the agent and, more problematically, the agent's utility would be unbounded with an unbounded horizon.

${ }^{2}$ For convenience, we discuss the model as though $Y_{t}^{0} \geq 0$, but this is not required. If $Y_{t}^{0}<0$, the agent must have cash (or credit) of $-Y_{t}^{0}$ available at the start of period $t$ to meet short-term liabilities.

${ }^{3}$ It is possible that investors may know that the cash flow $Y_{t}$ is at least $Y_{t}^{\prime}$, but can only enforce collection of $Y_{t}^{0}<Y_{t}^{\prime}$. In our model this can be handled by letting $\operatorname{Pr}\left(Y_{t}<Y_{t}^{\prime}\right) \rightarrow 0$.
} 
costless, $\lambda=1$. If $\lambda=0$, diversion is not profitable and the agency problem disappears. We consider $\lambda>0$.

At date $t$, after the cash flow $Y_{t}$ is realized, the agent may choose to quit or the contract may call for terminating the project. Either way, in the event of termination the assets of the firm are put to their best alternative use, generating a payoff of $L_{t}$, and the agent pursues his best outside option, receiving a payoff $R_{t} \geq 0$. In Section 4 we show how these termination payoffs may be endogenously determined based on the investors' ability to hire a new agent to run the firm, and the agent's ability to raise capital to start a new firm. For now, it is convenient to think of these as exogenous parameters.

In contrast to the operating cash flows, the asset termination payoff is observable and contractible. In particular, the division of the proceeds $L_{t}$ can be contractually specified. This modeling reflects the idea that the agent can divert the profits but not the assets. ${ }^{4}$ We assume the termination payoffs satisfy the following:

$$
L_{t} \geq e^{-r(s-t)} L_{s} \text { and } R_{t} \geq e^{-\gamma(s-t)} R_{s} \text { for } s>t .
$$

These properties follow immediately if the assets can be stored prior to optimal redeployment or liquidation and the agent can always wait for the best outside opportunity. If the project is terminated in period $t$, cash flows from the project cease, so that $Y_{s}=0$ for $s>t .^{5}$

The first-best value of the project just prior to the termination decision in period $s$ is given by

$$
V_{s}^{F B} \equiv \max _{\tau \geq s} E\left[\left(\sum_{s<t \leq \tau} e^{-r(t-s)} Y_{t}\right)+e^{-r(\tau-s)}\left(L_{\tau}+R_{\tau}\right)\right] .
$$

The maximization in $V_{s}^{F B}$ is over the termination date $\tau$. Let $T$ denote the first-best termination date, the first date for which the aggregate termination payoff exceeds the present value of the payoffs from continuing the project. Thus,

$$
V_{t}^{F B} \geq L_{t}+R_{t}
$$

with equality only for $t=T$. We assume $T>0$. An optimal contract leads to termination no later than period $T$, and so we can assume without loss of generality that the project is terminated by period $T$ and generates no

\footnotetext{
${ }^{4}$ Alternatively, we can interpret $R_{t}$ as including the value of any assets that can be diverted and interpret $L_{t}$ as the value of the remaining assets. We also assume that the agent cannot contract on $R_{t}$ (and use it as collateral). Any component of the agent's termination payoff that can be contracted on is included in $L_{t}$.

5 The liquidation and reservation values may be stochastic (in which case interpret $L_{t}$ nd $R_{t}$ as expected values) but in this case, as with the cash flows, we assume that there is no learning about their values prior to their realization.
} 
cash flows beyond $T .{ }^{6}$ For ease of presentation we assume the project has a finite economic life - that is, $T$ is finite. We then show in Section 2.8 how the optimal infinite horizon contract can be derived by taking the limit as $T \rightarrow \infty$. An example in Section 3.2 will consider this case.

\subsection{Contracts and timing}

Investors do not observe the realized cash flows or any concealment or diversion, and they do not observe the agent's consumption or saving. Investors observe only the payments and any reports (messages) they receive from the agent. So a contract can only specify, as a function of the history of the agent's payments and reports: (i) payments made from investors to the agent; and (ii) circumstances under which the project is terminated.

The timing is as follows. Each period, the agent receives a cash flow $Y_{t}$. Then the agent makes a payment to investors of $\hat{y}_{t} \geq Y_{t}^{0}$, concealing $Y_{t}-\hat{y}_{t}$, and the agent makes a report (or message) $m_{t}$ to investors. Given the history $h_{t}$ of payments and reports up to $t$ (including $\hat{y}_{t}$ and $m_{t}$ ) the contract specifies the payment made from investors to the agent, denoted by the function $d_{t}\left(h_{t}\right) \geq 0$. (Here we treat investors as a single group; later we disaggregate these cash flows into separate securities.) Then the agent chooses how much to consume - from concealed funds (at cost 1 $-\lambda$ ) and from his payment from the investors. Any remaining agent funds accumulate at the continuously compounded return $\rho \leq r .{ }^{7}$ Finally, before the next period's cash flow, the contract may call for investors to terminate the project. Let $p_{t}\left(h_{t}\right)$ denote the contractually specified termination probability in period $t$, specified as a function of the history. (We can also interpret probabilistic termination as the deterministic liquidation of the fraction $p_{t}$ of the assets if we assume constant returns to scale.) The agent may also terminate the project by quitting.

In summary, a contract consists of a pair of functions $(d, p)$ specifying the investors' payment to the agent and the probability of termination after any history. We consider two contractual environments. In the first, the contract signed in period 0 remains in force for the life of the project. In the second, the contract can be renegotiated and replaced with a new contract if all parties agree.

\footnotetext{
${ }^{6}$ To see this, note that for the agent not to quit, the agent must receive $a_{T} \geq R_{T}$ in continuation. Suppose investors receive $b_{T}$ in continuation. From (2), $a_{T}+b_{T} \leq L_{T}+R_{T}$. Thus, by terminating immediately and paying the agent $a_{T}-R_{T}$, investors get $L_{T}+R_{T}-a_{T} \geq b_{T}$.

${ }^{7}$ The restriction $\rho \leq r$ is an assumption that all of the agent's positive NPV investments are included in the project. Nothing changes if there were different returns on savings held within the firm versus held by the agent, as long as neither exceeds $r$.
} 


\section{Optimal Contract Design}

We begin by showing that the optimal contract does not require private saving by the agent or the use of messages, allowing us to simplify the problem. We then apply dynamic programming techniques to solve for the optimal contract.

\subsection{The nonnecessity of private saving}

Given any contract $\sigma=(d, p)$, the agent will choose an optimal strategy $\varphi$ that specifies, after any history, the cash flow to pay investors and any message to report to investors, an amount of cash flow to conceal and divert, a consumption and savings decision, and a quit decision. Rather than introduce notation to define this strategy space explicitly, we show in this section that a simpler strategy space will suffice.

We can think of the contract $\sigma$ as a mechanism that determines the agent's incentives regarding the strategy choice $\varphi$. As is standard in a mechanism design context, we begin with a Revelation-Principle type result that simplifies the set of strategies we need to consider for the agent. We can restrict attention to contracts in which the agent pays all the cash flows to investors, does no concealment or diversion or saving of funds, and does not quit before termination. Also, since the agent pays out all of the cash flow, no additional messages are necessary.

The reasoning behind this result is straightforward. Consider any contract for which the agent's optimal response entails concealing or diverting cash flows $\left(\hat{y}_{t}<Y_{t}\right)$. We can design a new contract in which the agent gives all cash flows to investors $\left(\hat{y}_{t}^{*}=Y_{t}\right.$ ), and investors then pay the agent (through $\left.d_{t}\right)$ an amount equal to the cash flow net of diversion costs $\left(\lambda\left(Y_{t}-\hat{y}_{t}\right)\right)$. Similarly, rather than private saving, the agent can give funds to investors, and receive them back in the future with interest $\rho$ under the contract (i.e., we can lower $d_{t}$ and raise $d_{t+s}$ ). These changes do not affect the agent's payoff, but lead to a weakly higher payoff for investors since both diversion and private savings are weakly inefficient $(\lambda \leq 1$ and $\rho \leq r)$. Finally, any contract that induces the agent to quit in period $t$ could be replaced with a contract that terminates in period $t$. This leads to the following result: ${ }^{8}$

Proposition 1. Given any contract $\sigma$ with optimal strategy $\varphi$ for the agent, there exists a contract $\sigma^{*}$ and optimal strategy $\varphi^{*}$ with the same payoff for the agent, a weakly higher payoff for investors, and with the property that the agent pays $\hat{y}_{t}^{*}=Y_{t}$ to investors, consumes $d_{t}^{*}$, does not quit prior to termination, and messages are unnecessary.

\footnotetext{
${ }^{8}$ Since this result is standard, we do not provide a formal proof. This avoids introducing notation that would be immediately superfluous. See the proof of Proposition 3 for a direct proof that $\hat{y}_{t}^{*}=Y_{t}$ is optimal.
} 
This result implies that we can restrict attention to contracts in which it is optimal for the agent to give all cash flows to investors, to consume all payments from investors, and to not save or divert cash flows. Of course, in deriving the optimal contract, we still need to make sure that a strategy for the agent with the above properties is incentive compatible.

We take the following approach to determining an optimal contract. First, we derive an optimal contract assuming that private saving is impossible, ignoring the associated incentive constraints. Then we will show that there is no incentive to save at the solution (these incentive constraints do not bind), so that we have a solution to the original contracting problem. In contrast, the incentive constraints related to cash flow diversion will bind.

\subsection{The dynamic programming approach}

Consider the simplified problem in which the strategy $\varphi$ specifies the agent's payment $\hat{y}_{t} \in\left[Y_{t}^{0}, Y_{t}\right]$ to investors, as well as whether the agent chooses to quit and terminate the contract, in each period. Let $\tau \leq T$ denote the (random) time at which the contract terminates. Without private saving, the agent's discounted payoff from continuing with the contract beyond period $t$ is given by:

$A_{t}(\sigma, \varphi)=E\left[\sum_{t<s \leq \tau} e^{-\gamma(s-t)}\left(\lambda\left(Y_{s}-\hat{y}_{s}\right)+d_{s}\right)+e^{-\gamma(\tau-t)} R_{\tau} \mid \sigma, \varphi, \tau>t\right]$.

The pair $(\sigma, \varphi)$ is incentive compatible if $\varphi$ maximizes this payoff given $\sigma$. Given the agent's strategy, the investors' discounted payoff at the end of period $t$ is

$$
B_{t}(\sigma, \varphi)=E\left[\sum_{t<s \leq \tau} e^{-r(s-t)}\left(\hat{y}_{s}-d_{s}\right)+e^{-r(\tau-t)} L_{\tau} \mid \sigma, \varphi, \tau>t\right] .
$$

Note that it is without loss of generality that the investors receive $L_{\tau}$ as any division of these proceeds can be contractually provided through the transfers to the agent.

The contract-strategy pair $(\sigma, \varphi)$ is optimal if it is incentive compatible and there is no other incentive-compatible pair that provides the same payoff to the agent and a higher payoff to investors. We say a contract is optimal if it is part of an optimal contract-strategy pair.

We solve for an optimal contract using dynamic programming. ${ }^{9}$ Because cash flows are independent over time and there is no private saving, the functions $A_{t}$ and $B_{t}$ are common knowledge in period $t$ and independent of the prior history. As a result, an optimal contract must be optimal

\footnotetext{
9 See Spear and Srivastava (1987), and Green (1987) for discussions of this approach to solving dynamic contracting problems.
} 


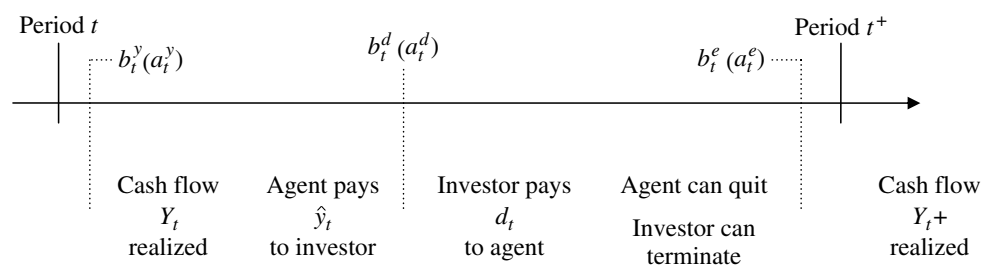

Figure 1

The timeline of the model

The continuation functions $b_{t}^{y}, b_{t}^{d}$, and $b_{t}^{e}$ represent the maximum investor payoffs given promised payoffs to the agent at the various points in the period.

after any history. Otherwise, we could find an alternative contract that leaves the agent's payoff and incentives unchanged, but raises the payoff to investors. Therefore, given the agent's payoff $a$ at the end of period $t$, the investors' payoff is given by

$$
b_{t}^{e}(a) \equiv \max _{\sigma, \varphi} B_{t}(\sigma, \varphi) \text { subject to } A_{t}(\sigma, \varphi)=a=\max _{\varphi^{\prime}} A_{t}\left(\sigma, \varphi^{\prime}\right) .
$$

We call $b_{t}^{e}$ the end-of-period $t$ continuation function. It gives the highest payoff attainable by investors given the payoff $a$ for the agent. If the payoff $a$ is unattainable, we define $b_{t}^{e}(a)=-\infty$. This continuation function fully characterizes the payoff-relevant attributes of the project beyond period $t$. As a result, the history can be summarized by the current value $a$ of the agent's continuation payoff. An optimal contract provides incentives by effectively specifying how $a$ varies with the history of the agent's payments to investors.

As illustrated in Figure 1, $b_{t}^{e}$ is the continuation function as of the end of period $t$. We can also define continuation functions at earlier stages in period $t: b_{t}^{d}$ is the continuation function just before the payment to the agent in period $t$, and $b_{t}^{y}$ is the continuation function just before the cash flow $Y_{t}$ is realized. Our analysis proceeds by characterizing these continuation functions, working from the end of period $t$ to the beginning.

\subsection{Period $T$}

The project has a finite economic life and will be terminated no later than period $T$. Therefore we can define $b_{T}^{e}(a)$, the continuation function for the end-of-period $T$, and solve for earlier continuation functions recursively.

After period $T$, any payments to the agent are transfers from investors. Since $\gamma \geq r$, it is efficient to make any such payments in the following period, which we denote by $T^{+}$. We can represent this by the end-of-period 
$T$ continuation function:

$$
b_{T}^{e}(a)= \begin{cases}-e^{(\gamma-r)\left(T^{+}-T\right)} a & \text { for } a \geq 0 \\ -\infty & \text { for } a<0\end{cases}
$$

That is, the most efficient way to provide the agent with a payoff of $a$ after the project is terminated is to pay the agent $e^{\gamma\left(T^{+}-T\right)} a$ in the following period $T^{+}$. The continuation function represents the cost of this payment to investors given the discount rate $r$. Because the agent cannot be induced to pay investors once the project is terminated, payoffs $a<0$ are infeasible. Note that while it is feasible to pay the agent after period $T$, given the difference in discount rates, such payments are (weakly) inefficient. We will see that with the optimal contract, all payments will occur before the end of period $T$.

Given the continuation function (3), we can work backward to determine recursively the continuation function $b_{t}^{e}$ in earlier periods $t<T$. Following the timeline in Figure 1, our analysis first takes $b_{t}^{e}$ as given and determines $b_{t}^{d}$, summarizing its properties in Proposition 2. Then taking $b_{t}^{d}$ as given we determine $b_{t}^{y}$, summarizing its properties in Proposition 3. Finally, taking $b_{t}^{y}$ as given we determine $b_{t^{-}}^{e}$, summarizing its properties in Proposition 4. In doing so, we consider the different actions that can be taken during each stage of a period. While $b_{T}^{e}$ is linear for $a \geq 0$, in what follows we show inductively that $b_{t}^{e}$ is generally concave, as illustrated in Figure 2. Intuitively, the lower the agent's share of the project payoff, the greater the agency costs. Thus, the gain to investors from lowering the agent's payoff decreases as $a_{t}^{e}$ falls.

\subsection{Termination and payments to the agent}

In this section, we describe how to compute $b_{t}^{d}$ (the continuation function just prior to the period $t$ quit/termination decisions and payments to the agent) from $b_{t}^{e}$. This involves determining the optimal cash payment from investors to the agent and the optimal termination probability.

The agent has the option to quit and receive $R_{t}$. Thus prior to the termination decision, the lowest feasible payoff for the agent is $R_{t}$, so $b_{t}^{d}$ will be defined for $a_{t}^{d} \geq R_{t}$. Also, given the ability to terminate probabilistically, all payoffs within the convex hull of $\left(L_{t}, R_{t}\right)$ and the payoff possibilities defined by $b_{t}^{e}$ are feasible. The frontier of this set is given by a line from $\left(L_{t}, R_{t}\right)$ that is tangent to $b_{t}^{e}$, as shown in Figure 2. We denote by $a_{t}^{L}$ the agent's payoff at the point of tangency, and let $l_{t}$ be the marginal payoff of investors along this tangent line (Proposition 2 has a formal definition). An agent payoff $a_{t}^{d} \in\left[R_{t}, a_{t}^{L}\right]$ is optimally achieved 


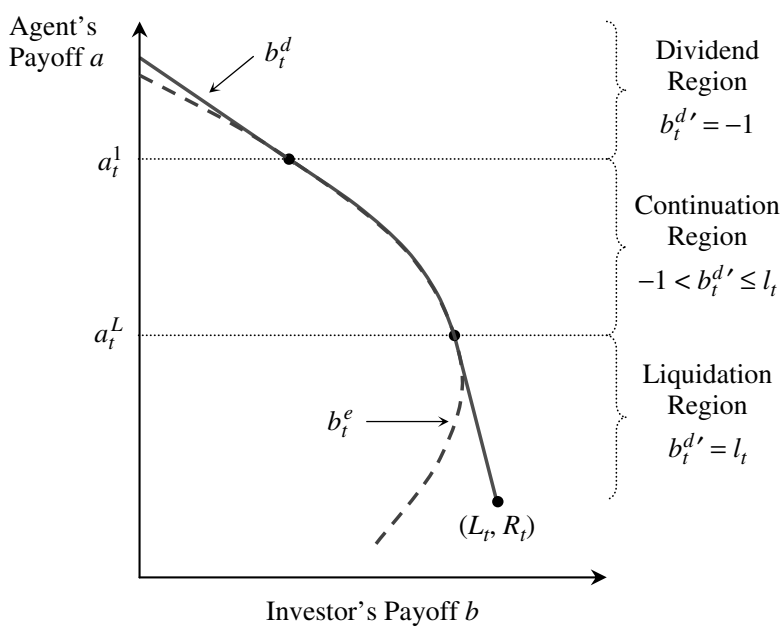

Figure 2

Constructing the continuation function $b_{t}^{d}$ from $b_{t}^{e}$

Current cash payments are cheaper than promises of future payments if the agent's continuation payoff is above $a_{t}^{1}$. If the agent's continuation payoff is below $a_{t}^{L}$ it is optimal to randomize between termination and continuing with a promise of $a_{t}^{L}$.

by terminating with probability

$$
p_{t}\left(a_{t}^{d}\right)=\frac{a_{t}^{L}-a_{t}^{d}}{a_{t}^{L}-R_{t}}
$$

and otherwise continuing with continuation payoff $a_{t}^{L}$. Note that we have changed notation by writing $p_{t}$ as a function of the state variable $a_{t}^{d}$ alone, rather than the entire history $h_{t}$. This is because the agent's continuation payoff captures the payoff-relevant information regarding the history. (We will do the same for $d_{t}$ below.)

When will the optimal contract provide a payment $d_{t}>0$ to the agent? At this stage, there are two ways to compensate the agent - by paying him cash in the current period and by promising a continuation payoff (the prospect of cash in the future). The optimal contract uses whichever form of compensation is least expensive for investors. Since paying the agent one dollar in cash costs investors one dollar, cash payments are used if the slope of the continuation function is below -1 ; that is, if paying the agent in the future would cost investors more than one dollar. Since $b_{t}^{e}$ is concave, there is a threshold level of the agent's payoff, $a_{t}^{1}$, such that cash payments are used above this threshold. That is, the agent receives cash equal to

$$
d_{t}\left(a_{t}^{d}\right)=\max \left(a_{t}^{d}-a_{t}^{1}, 0\right) .
$$


As a result of these transformations, note from Figure 2 that the continuation function $b_{t}^{d}$ has the properties: ${ }^{10}$

$$
b_{t}^{d} \text { is concave with } b_{t}^{d \prime}(a) \geq-1 \text {. }
$$

We will exploit these properties in determining the optimal way to provide the agent with the incentives to pay out all of the project cash flows.

At the end of the project's life, $T$, termination is (by definition) optimal. In this case we set $a_{T}^{L}=\infty$ (the same is true in any period $t$ in which termination is optimal). Also, any cash payments made to the agent should be made immediately, due to the difference in discount rates. That is, $a_{T}^{1}=R_{T}$. As a result, $p_{T}=1, d_{T}=a_{T}^{d}-R_{T}$, and $b_{T}^{d}\left(a_{T}^{d}\right)=L_{T}-\left(a_{T}^{d}-R_{T}\right)$.

We conclude this section with a formal summary of the construction of $b_{t}^{d}$ :

Proposition 2. Given $b_{t}^{e}$ concave, let

$$
l_{t}=\sup \left\{\frac{b_{t}^{e}(a)-L_{t}}{a-R_{t}}: a>R_{t}\right\} .
$$

Then if $l_{t}>-1$, define

$$
\begin{gathered}
a_{t}^{L}=\inf \left\{a>R_{t}: b_{t}^{e \prime}(a) \leq l_{t}\right\}, a_{t}^{1}=\inf \left\{a: b_{t}^{e \prime}(a) \leq-1\right\} \\
b_{t}^{d}\left(a_{t}^{d}\right)= \begin{cases}b_{t}^{e}\left(a_{t}^{1}\right)-\left(a_{t}^{d}-a_{t}^{1}\right) & \text { for } a_{t}^{d} \geq a_{t}^{1} \\
b_{t}^{e}\left(a_{t}^{d}\right) & \text { for } a_{t}^{L} \leq a_{t}^{d} \leq a_{t}^{1} \\
b_{t}^{e}\left(a_{t}^{L}\right)-l_{t}\left(a_{t}^{L}-a_{t}^{d}\right) & \text { for } R_{t} \leq a_{t}^{d}<a_{t}^{L} \\
-\infty & \text { for } a_{t}^{d}<R_{t}\end{cases}
\end{gathered}
$$

If $l_{t} \leq-1$, termination is optimal. In this case, define $a_{t}^{L}=\infty, a_{t}^{1}=R_{t}$ and

$$
b_{t}^{d}\left(a_{t}^{d}\right)= \begin{cases}L_{t}-\left(a_{t}^{d}-R_{t}\right) & \text { for } a_{t}^{d} \geq R_{t} \\ -\infty & \text { for } a_{t}^{d}<R_{t}\end{cases}
$$

Finally, note that $b_{t}^{d}$ satisfies (6).

\subsection{The intra-period agency problem}

In this section, we solve for $b_{t}^{y}$ (the continuation function before the cash flow $Y_{t}$ is realized) given the continuation function $b_{t}^{d}$. To do so, we solve the intra-period agency problem by providing the agent with incentives to pay the cash flow to investors.

${ }^{10}$ The continuation function need not be differentiable. Throughout the article, at any kink in a concave function $f$, we interpret $f^{\prime}(x)$ as any supergradient of $f$ at $x$. 
Consider the agent's problem. After the cash flow $Y_{t}$ is realized, the agent chooses a payment $\hat{y}_{t}$ to make. Based on $\hat{y}_{t}$, according to the contract the agent receives some continuation payoff $a_{t}^{d}$. An optimal contract chooses the continuation payoff $a_{t}^{d}$ as a function of the agent's payment so as to provide incentives for the agent to pay out all of the cash flow (i.e., choose $\hat{y}_{t}=Y_{t}$ ). This must be done in a way that maximizes the investors' expected payoff. This can be written as the following optimization problem:

$$
\begin{aligned}
b_{t}^{y}\left(a_{t}^{y}\right)= & \max _{a_{t}^{d}(\cdot)} E\left[Y_{t}+b_{t}^{d}\left(a_{t}^{d}\left(Y_{t}\right)\right)\right] \\
& \text { s.t. (IC) } a_{t}^{d}\left(Y_{t}\right) \geqslant a_{t}^{d}(y)+\lambda\left(Y_{t}-y\right) \text { for all } y \in\left[Y_{t}^{0}, Y_{t}\right] \\
& (\mathrm{PK}) E\left[a_{t}^{d}\left(Y_{t}\right)\right]=a_{t}^{y}
\end{aligned}
$$

The objective function is the expected payoff of investors. Investors receive the cash flows plus the highest possible continuation payoff $b_{t}^{d}$ given that the agent receives $a_{t}^{d}$. The first constraint is the agent's incentive compatibility constraint - it is optimal for the agent to pay all the cash flows to investors, rather than underreport and consume some of the cash flows himself. The second constraint is the "promise-keeping" constraint that guarantees the agent's expected continuation payoff matches his promised continuation payoff $a_{t}^{y}$ at the start of the period.

To solve (7), note first that the (IC) constraint is equivalent to $a_{t}^{d}(y)-\lambda y$ increasing in $y$, or equivalently, $a_{t}^{d^{\prime}}(y) \geq \lambda$. The promisekeeping constraint fixes the mean payoff to the agent, so different choices of $a_{t}^{d}$ affect its variability. But since $b_{t}^{d}$ is concave, it is optimal to minimize the variability of $a_{t}^{d}$. This is done by setting $a_{t}^{d \prime}(y)=\lambda$, so that the incentive constraints just bind. We state this formally below.

Proposition 3. Given $b_{t}^{d}$ satisfying (6) and with $\mu_{t} \equiv E\left[Y_{t}\right]$, the optimal continuation payoff for the agent given reported cash flow y is given by

$$
a_{t}^{d}(y)=a_{t}^{y}+\lambda\left(y-\mu_{t}\right) .
$$

This yields the start of period continuation function,

$$
b_{t}^{y}\left(a_{t}^{y}\right)=\mu_{t}+E\left[b_{t}^{d}\left(a_{t}^{y}+\lambda\left(Y_{t}-\mu_{t}\right)\right)\right]
$$

which is concave.

This result has two important consequences. First, it implies that the marginal benefit to the agent from paying out a higher cash flow is constant. As a result, since the agent's discount rate exceeds the return to private savings, there is no benefit to concealing cash flows today in order to report higher cash flows in the future. Thus, the agent has no incentive to use private savings, justifying our solution methodology. 
Corollary 1. In the optimal contract without private saving, the agent has no incentive to save. Thus, this contract is optimal even with the possibility of private saving.

Second, we can combine (5) and (8) to characterize the cash payments to the agent in the optimal contract. This leads to the following:

Corollary 2. The cash payments to the agent correspond to a levered equity claim. That is,

$$
d_{t}=\lambda \max \left(Y_{t}-D_{t}, 0\right)
$$

where $D_{t}=\mu_{t}+\lambda^{-1}\left(a_{t}^{1}-a_{t}^{y}\right)$.

Thus, each period the optimal contract effectively pays the agent a share $\lambda$ of a levered equity claim on the firm's cash flows. While a similar characterization holds for static cash flow diversion models, what is special here, and what we have yet to determine, are the dynamics of the underlying leverage. We will accomplish this in two stages. First, we complete our recursive characterization of the optimal contract. Then, in Section 3, we show how the optimal contract can be implemented using standard debt and equity claims.

\subsection{The optimal contract}

Thus far, we have described how to compute the continuation functions $b_{t}^{d}$ and $b_{t}^{y}$ given the continuation function $b_{t}^{e}$ at the end of period $t$. We now derive the continuation function $b_{t^{-}}^{e}$ (the continuation function at the end of the prior period $t^{-}$) and combine the results to complete our recursive characterization of the optimal contract.

Moving from the start of period $t$ to the end of the prior period involves discounting the payoffs of the agent and investors. To provide the agent with a payoff $a$ at the end of period $t^{-}$, he must be paid $a$ plus interest at rate $\gamma$ at the start of period $t$. The investors' continuation payoff is then discounted at rate $r$. This implies the following characterization of the continuation payoff for investors:

Proposition 4. Given $b_{t}^{y}$, the continuation function at the end of the prior period $t^{-}$is given by

$$
b_{t^{-}}^{e}\left(a_{t^{-}}^{e}\right)=e^{-r\left(t-t^{-}\right)} b_{t}^{y}\left(e^{\gamma\left(t-t^{-}\right)} a_{t^{-}}^{e}\right),
$$

which is concave.

Thus, starting from the end-of-period $T$ continuation $b_{T}^{e}$ defined by (3), the constructions in Propositions 2, 3 and 4 recursively solve for the continuation function at all earlier points in the contract. 
Having solved for the optimal continuation function recursively, we now show how it determines the optimal contract. The dynamics of the contract are governed by a single state variable representing the current promised continuation payoff for the agent. From our preceding results, the evolution of this state variable can be summarized as in Figure 3. Given a promised payoff of $a_{s}^{e}$ at the end-of-period $s=t^{-}$, the agent will have a promised payoff of $a_{t}^{y}$ at the beginning of period $t$ (accounting for the agent's discount rate). Then, given the realization of the cash flow $Y_{t}$, the agent's payoff becomes $a_{t}^{d}$. The promised payoff $a_{t}^{d}$ determines the cash payment to the agent $d_{t}$ and the termination probability $p_{t}$. The agent's continuation payoff is $a_{t}^{e}$ if not terminated and $R_{t}$ if terminated. When $a_{t}^{d} \geq a_{t}^{L}$, the termination probability $p_{t}$ is zero, and the agent's continuation payoff $a_{t}^{d}=d_{t}+a_{t}^{e}$. When $a_{t}^{d}<a_{t}^{L}$, the termination probability $p_{t}$ is positive and the agent's cash payment $d_{t}=0$. The agent's expected payoff is $a_{t}^{d}=\left(1-p_{t}\right) a_{t}^{e}+p_{t} R_{t}$. Figure 3 summarizes the behavior of the optimal contract starting from some initial promised payoff for the agent. Next we examine how initial payoffs are determined.

\subsection{Initiating the contract}

The choice of an initial contract in period 0 corresponds to the choice of an initial payoff pair from the payoff possibility set. This choice is determined by the competitive environment in which the contract is signed.

Recall that the agent's initial wealth is given by $Y_{0}$. The project requires an initial investment of $I$, which will be funded jointly by the agent and investors. Normally, we think of a contract being proposed, and if accepted by the agent and investors, the investment is made and the project begins.

An equivalent way to describe this is as follows. Investors commit $I$ up front. The agent then pays $\hat{y}_{0} \leq Y_{0}$ to investors. If the agent's contribution is acceptable, the project begins. If it is not acceptable, the project is terminated and investors recover the investment $I$. Thus, the agent can

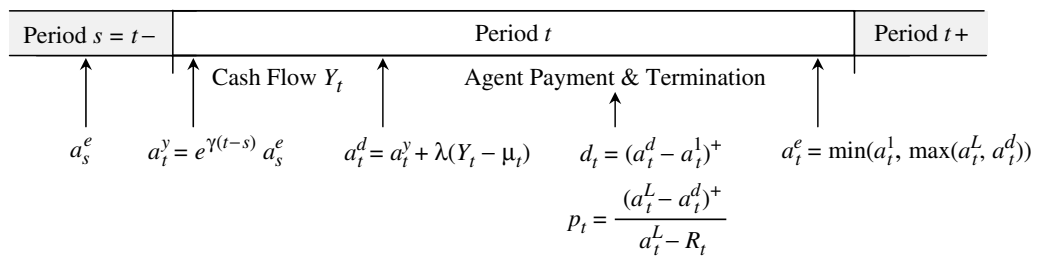

Figure 3

Dynamics of the agent's continuation payoff, payments, and termination

The agent's continuation payoff evolves as follows. A promised payoff $a_{s}^{e}$ at the end of period $s$ becomes a payoff $a_{t}^{y}$ at the start of period $t$, reflecting the agent's discount rate, which becomes a payoff $a_{t}^{d}$ depending on the realization of the cash flow $Y_{t}$. The continuation payoff $a_{t}^{d}$ determines the agent's cash payment, $d_{t}$, and the termination probability, $p_{t}$. At the end of period $t$ the agent's continuation payoff is $a_{t}^{e}$, reflecting the agent's cash payment and the termination decision. 
reject the proposal by choosing not to contribute funds. Investors can reject the proposal by terminating in period 0 .

This description fits the termination stage of period 0 in our model. Here, we specify termination payoffs $\left(L_{0}, R_{0}\right)$ with $L_{0} \geq I$, because investors can recover at least $I$ by terminating immediately. (We allow $L_{0}>I$ in case there are pre-existing assets that can also be liquidated.) Thus, the set of available contracts can be interpreted as the continuation function $b_{0}^{d}$.

If investors compete to fund the project, then we expect the initial contract to be the best possible for the agent such that investors earn nonnegative profits. That is, the agent offers to contribute $Y_{0}$ and gets the highest payoff possible such that investors break even:

$$
a_{0}^{d}=\sup \left\{a: b_{0}^{d}(a) \geq I-Y_{0}\right\} .
$$

Note that because $b_{0}^{d \prime} \geq-1$, contributing the full $Y_{0}$ is optimal, and also $a_{0}^{d} \geq R_{0}+Y_{0}$.

Alternatively, if investors own the rights to the project, and there are multiple agents with the same wealth who compete for the right to manage it, then we expect the contract to be the best possible for investors such that the agent earns nonnegative profits:

$$
a_{0}^{d}=\underset{a \geq R_{0}+Y_{0}}{\arg \max } b_{0}^{d}(a) .
$$

See Figure 4. In either case, investors earn $Y_{0}+b_{0}^{d}\left(a_{0}^{d}\right)-I$. The project is started with probability 1 as long as $a_{0}^{d} \geq a_{0}^{L} .{ }^{11}$ The agent receives an immediate cash payment if $a_{0}^{d} \geq a_{0}^{1}$.

Of course, cases in which both investors and the agent have some market power are possible. For example, investors may own the rights to the project, and one agent may be a better choice to manage the project (e.g., he has a higher $\mu_{t}$, a lower $\lambda$, etc.). This case will lead to a bargaining outcome between the two extremes indicated above.

\subsection{Infinite horizon}

Our analysis can be extended to the infinite horizon case, as we briefly describe here. Consider an infinite horizon setting that we arbitrarily truncate to a $T$-period horizon by forcing liquidation at the end of period $T$. Let $\hat{b}_{t}^{d}$ be the optimal continuation function for this truncated model. Then in the final period, $\hat{b}_{T}^{d}(a)=L_{T}+R_{T}-a$ for $a \geq R_{T}$, and we can solve for earlier periods as before. Now let $b_{t}^{d}$ be the optimal continuation function with an infinite horizon. Because the contract could call for

${ }^{11}$ If $I-Y_{0}$ is large, it is possible that $a_{0}^{d}<a_{0}^{L}$. In that case, $p_{0}>0$ and the startup of the project involves a lottery. The agent takes an all-or-nothing bet with his wealth, and if he wins the project is started with an agent payoff of $a_{0}^{L}$. If he loses, he loses his initial wealth and the project is not started. 


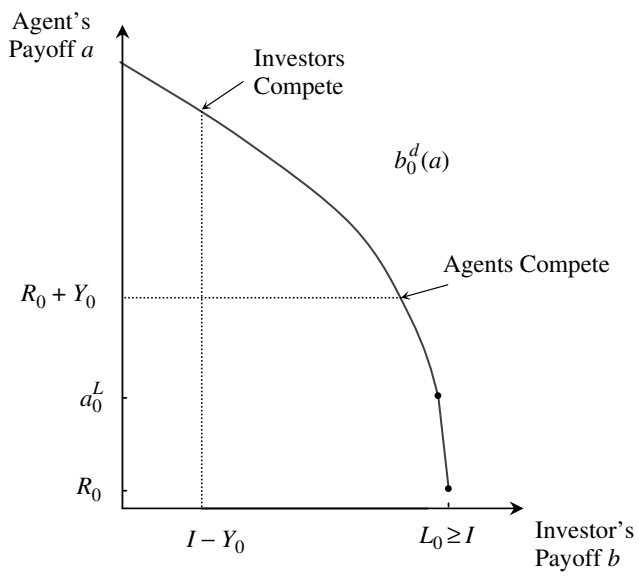

\section{Figure 4}

Initial contract payoffs

At initiation, the contract must offer the agent at least his opportunity cost plus his investment, $R_{0}+Y_{0}$, and must offer the investor at least his investment, $I-Y_{0}$. Relative bargaining power will determine the exact location of the initial payoffs on the Pareto frontier, $b_{0}^{d}$.

liquidation in period $T$,

$$
\hat{b}_{T}^{d}(a)=L_{T}+R_{T}-a \leq b_{T}^{d}(a) \leq V_{T}^{F B}-a
$$

Therefore,

$$
\hat{b}_{t}^{d}(a) \leq b_{t}^{d}(a) \leq \hat{b}_{t}^{d}(a)+e^{-r(T-t)}\left(V_{T}^{F B}-L_{T}-R_{T}\right)
$$

and the optimal continuation function for the infinite horizon model coincides with the limit of the truncated models as long as

$$
\lim _{T \rightarrow \infty} e^{-r T}\left(V_{T}^{F B}-L_{T}-R_{T}\right)=0
$$

Condition (13) is satisfied in all reasonable settings (e.g., it is sufficient that $V_{0}^{F B}$ is well defined and $L_{T}$ is bounded below). In this case we can solve for the optimal continuation function for the infinite horizon case by considering the limit of finite horizon models. ${ }^{12}$

\subsection{Renegotiation-proofness}

In the analysis above, we assumed that the agent and investors commit to a contract for the life of the project. We now consider the possibility that they cannot commit not to renegotiate the contract, and we show its effect on the possible continuation payoffs in the optimal mechanism.

\footnotetext{
12 This limit exists for stationary settings without renegotiation; with renegotiation there is the possibility of cycles as $T$ grows large. See DeMarzo and Sannikov (2006) for a discussion of solving for the renegotiation proof contract with an infinite horizon.
} 
Consider the continuation function $b_{t}^{d}$ representing the highest continuation payoff to investors for a given continuation payoff to the agent just prior to period $t$ 's payment from investors to the agent. Define

$$
a_{t}^{R}=\inf \left\{a: b_{t}^{d \prime}(a) \leq 0\right\} .
$$

Then $a_{t}^{R}$ maximizes $b_{t}^{d}$, so that

$$
b_{t}^{d}(a)<b_{t}^{d}\left(a_{t}^{R}\right) \text { for } a<a_{t}^{R} .
$$

A contract that, after some history, offers the agent a continuation payoff less than $a_{t}^{R}$ at this stage is Pareto inferior. Given the opportunity, the agent and investors will agree to replace it with a new contract that yields a higher payoff for all; for example, they may agree to continue with continuation payoff $a_{t}^{R}$ for the agent instead.

Thus, if renegotiation is possible, ${ }^{13}$ continuation payoffs $a<a_{t}^{R}$ are infeasible. Said another way, a renegotiation-proof contract must always use continuation payoffs on the Pareto frontier of the payoff possibility set. With a finite horizon, the result that renegotiation-proofness is equivalent to the contract being sequentially undominated (in terms of payoffs) is shown by Hart and Tirole (1988). ${ }^{14}$

Consider the termination decision. Termination is inefficient if $\left(L_{t}, R_{t}\right)$ is inferior to an available continuation payoff, which is equivalent to $l_{t}>0$ (this corresponds to $b_{t}^{d}$ having an upward sloping portion). The following proposition establishes that to make the contract renegotiation-proof it is sufficient to rule out termination and change our definition of $b_{t}^{d}$ when $l_{t}>0$.

Proposition 5. The optimal renegotiation-proof continuation function is constructed according to Propositions 2, 3, and 4, with the exception that if $l_{t}>0$, then $a_{t}^{R}=a_{t}^{L}$ and

$$
b_{t}^{d}\left(a_{t}^{d}\right)= \begin{cases}b_{t}^{e}\left(a_{t}^{1}\right)-\left(a_{t}^{d}-a_{t}^{1}\right) & \text { for } a_{t}^{d} \geq a_{t}^{1} \\ b_{t}^{e}\left(a_{t}^{d}\right) & \text { for } a_{t}^{L} \leq a_{t}^{d} \leq a_{t}^{1} \\ -\infty & \text { for } a_{t}^{d}<a_{t}^{L}\end{cases}
$$

13 This is likely the case. In the United States, courts will generally not enforce contractual provisions against renegotiation. This places restrictions on what can be achieved by an optimal contract and is a form of contract incompleteness.

${ }^{14}$ Hart and Moore (1998) and Hart (1995) do not use this approach, but instead assume that one party can invoke renegotiation to a new outcome unilaterally (see, e.g., Hart and Moore (1998:20)). For example, suppose a contract has payoffs $(6,4)$ but party 2 can threaten an action that leads to $(0,3)$. These articles assume that this threat can provoke renegotiation to a new outcome such as $(5,5)$. In addition to a lack of enforceability, their assumption implicitly assumes one party has greater commitment power than the other. 
When $l_{t}>0$, termination will not occur in period $t$, which will limit the incentives that can be provided and lower the continuation functions in prior periods relative to the case with commitment. Working backward, after several periods without the possibility of termination, the continuation function may fall to the point that $l_{s} \leq 0$ in period $s<t$, and termination is renegotiation-proof. ${ }^{15}$

Renegotiation-proofness reduces the payoffs associated with the project, and will alter the numerical values of $a_{s}^{1}, a_{s}^{L}$, etc. in periods $s<t$. However, the underlying dynamics of the optimal contract still correspond to those in Figure 3 above, and so are unchanged.

\section{Implementation with Debt and Equity}

In this section we describe how the optimal contract can be implemented using standard securities. We then solve a numerical example and compute the optimal capital structure. Finally, we explore the role of each security by considering comparative statics.

\subsection{Optimal security design}

Our main result is that the optimal contract can be implemented by funding the project using long-term debt, a credit line, and equity. Thus, these securities are optimal in our setting. They are defined as follows:

Long-Term Debt: Long-term debt with maturity $T^{*}$ is characterized by a sequence of fixed payments $x_{t}$ for $0<t \leq T^{*}$. A final payment $f_{T^{*}}$ is due at maturity. If a payment is not made, the agent is in default.

Credit Line: A credit line is characterized by an interest rate $\hat{r}$ and credit limit $c_{t}^{L}$ for $t \geq 0$. The agent can draw on the credit line, up to the credit limit, at any time. No payments need be made on the credit line unless the outstanding balance (including accrued interest) exceeds the credit limit at the end of the period. If this excess is not paid, the agent is in default.

Equity: Cash flows not used to pay debt claims may be used to pay a dividend to equity holders. Dividends are paid in proportion to share ownership.

Default: If default occurs in period $t$, creditors seize all verifiable cash flows ( $Y_{t}^{0}$ plus any current withdrawal on the credit line). Remaining unmade payments $z>0$ convert to liquidation rights according to a contractually specified notional value $N_{t}$ of the equity. That is, instead of receiving $z$, debt holders terminate the project with probability

\footnotetext{
${ }^{15}$ We have defined renegotiation-proofness here for a finite horizon setting. With an infinite horizon, the definition of renegotiation-proofness is more problematic. Even in a stationary environment, the limit of finite horizon contracts may not exist because the optimal renegotiation-proof contract may involve cycles with termination possible in some periods and not in others. See DeMarzo and Sannikov (2006) for a discussion of how to compute the optimal stationary renegotiation-proof infinite horizon contract.
} 
$p_{t}(z)=z / N_{t}$, and with probability $1-p_{t}(z), z$ is forgiven. In the event of early termination debt holders receive the liquidation payoff $L_{t}$.

The definitions of equity, long-term debt and the credit line look like standard securities used in practice. The notion of default is somewhat nonstandard, as we allow for stochastic termination. However, our modeling allows liquidation to be constant returns to scale, in which case we can interpret this as nonstochastic liquidation of the fraction $p_{t}$ of the firm. ${ }^{16}$ Note also that we do not specify how the proceeds $L_{t}$ are divided among the debt holders. Different priority rules can be used. While the specific priority rule used affects the pricing of the individual securities, it has no consequence regarding the agent's incentives.

We now state our main theorem showing that the optimal contract can be implemented with the long-term debt, equity, and line of credit described above:

Theorem 1. The optimal contract is implemented by a combination of equity, long-term debt, and a credit line. The agent holds the fraction $\lambda$ of the equity, and the remaining $1-\lambda$ is held by investors. In addition, investors hold long-term debt with maturity $T^{*}=\min \left\{t: l_{t} \leq-1\right\} \leq T$, final payment $f_{T^{*}}=L_{T^{*}}$, and fixed payments of

$$
x_{t}=\mu_{t}+\lambda^{-1}\left[a_{t}^{1}-e^{\gamma\left(t-t^{-}\right)} a_{t^{-}}^{1}\right] \text { for } 0<t \leq T^{*} .
$$

The credit line has interest rate $\hat{r}=\gamma$, and a credit limit given by

$$
c_{t}^{L}=\lambda^{-1}\left(a_{t}^{1}-a_{t}^{L}\right) \text { for } 0 \leq t<T^{*} .
$$

In the event of default, the notional value of equity is given by

$$
N_{t}=\lambda^{-1}\left(a_{t}^{L}-R_{t}\right) \text { for } 0 \leq t<T^{*} .
$$

The initial draw on the credit line in period 0 is given by $c_{0}^{d}=\lambda^{-1}\left(a_{0}^{1}-a_{0}^{d}\right)$, where $a_{0}^{d}$ is determined by the relative market power of the agent and investors as in Section 2.7. ${ }^{17}$ Finally, in period $T^{*}, c_{T^{*}}^{L}=0$, and $N_{T^{*}}=L_{T^{*}}$. Given this contract, the agent pays the long-term debt coupon and then uses remaining cash to pay down the credit line. Once the credit line is fully repaid, excess cash is used to pay a dividend. In period $T^{*}$, the agent terminates the project.

The intuition behind this implementation is as follows. The only historydependent variable in the securities above is the balance on the credit line.

\footnotetext{
16 Termination is not randomized in the continuous-time version of this model; see Biais et al. (2007) and DeMarzo and Sannikov (2006).

17 A negative draw implies that a dividend is paid in period 0.
} 
The agent's continuation payoff at any point in time is "tracked" by this balance. That is, given credit line balance $c_{t}^{d}$, the agent's continuation payoff is given by

$$
a_{t}^{d}=a_{t}^{1}-\lambda c_{t}^{d} .
$$

A zero balance on the credit line corresponds to a continuation payoff of $a_{t}^{1}$, and any additional cash flow results in a dividend payment. In contrast, when the credit line is at its limit $c_{t}^{L}$, the agent's continuation payoff equals, using (15), $a_{t}^{1}-\lambda c_{t}^{L}=a_{t}^{1}-\lambda\left(\lambda^{-1}\left(a_{t}^{1}-a_{t}^{L}\right)\right)=a_{t}^{L}$. In this case, a cash shortfall leads to default and possible termination. Repaying a dollar on the credit line increases the agent's continuation payoff by $\lambda$. As a result, the agent has no incentive to divert the cash flows.

To understand the debt payments, $x_{t}$, suppose the agent has paid off the credit line in period $t^{-}$. Then the agent's expected credit line position in the next period (before paying a dividend) is $x_{t}-\mu_{t}$, implying from (17) an expected continuation payoff of $a_{t}^{1}-\lambda\left(x_{t}-\mu_{t}\right)$. To deliver a continuation payoff of $a_{t^{-}}^{1}$ in the prior period, we must have

$$
a_{t^{-}}^{1}=e^{-\gamma\left(t-t^{-}\right)}\left[a_{t}^{1}-\lambda\left(x_{t}-\mu_{t}\right)\right]
$$

Solving the above for $x_{t}$ yields (14).

Finally, recall that termination is used to provide the agent with appropriate incentives to repay investors. Therefore, the notional value $N_{t}$ is based on the value to the agent of avoiding termination and receiving $a_{t}^{L}$ versus the outside option $R_{t}$.

Of course, this implementation is not unique. For example, we can aggregate the three securities into a single security without changing the agent's incentives. However, the implementation we have described is natural and corresponds well to securities observed in practice.

Theorem 1 characterizes the optimal dynamic capital structure: the coupon/maturity structure of the long-term debt; the interest rate and limit on the credit line; and the equity fraction given to outside investors. With high cash flows, the debt coupon is paid, the credit line is paid down, and any remainder goes for dividends. With low cash flows, the agent draws on the credit line. Hence the firm's debt-equity ratio moves inversely with realized earnings and will be strongly history dependent.

\subsection{A numerical example}

We illustrate our security design results with an example. We will consider a stationary environment for which $T \rightarrow \infty$. A project generates perpetual risky cash flows that are i.i.d., uniformly distributed on $\{0,1,2, \ldots 20\}$. The agent has no initial capital $\left(Y_{0}=0\right)$ and a reservation wage $R_{t}=0$. The project has a liquidation value of $L_{t}=75$. The riskless rate of interest is $10 \%(r=9.53 \%$, continuously compounded $)$ and the agent's subjective 
discount rate for consumption is $10.5 \%(\gamma=9.98 \%)$. Since $\gamma>r$, the agent would like to raise funds to finance current consumption as well as to finance the initial investment $I$ required to start the business. Assume that the financial market is competitive so that in financing the project, investors break even and the agent captures all of the rents.

Given the expected cash flow of 10 per period, in a perfect capital market (i.e., $\lambda=0$ ) the agent would sell all equity to investors, raise funds of $10 / 10 \%=100$, invest $I$, and immediately consume $100-I$ (if $I>100$, the project is not worth funding). Investors would then receive all future cash flows as dividends. Selling the equity is optimal for the agent even if no external funds are required to start the project, as the value paid by investors exceeds value of the equity to the agent, $10 / 10.5 \%=95.24$.

Now introduce the agency problem: the agent privately observes the cash flows and can divert them for his own consumption. Suppose that this diversion comes at no cost, i.e., $\lambda=1$. By Theorem 1 , in this case the equity is held entirely by the agent, and long-term debt and a line of credit are sufficient for the investors.

The continuation function $b_{t}^{d}$ for $T$ large is shown in Figure 5. In this case, $a^{L}=9.05$ and $a^{1}=35.83$ (given the solution is stationary we drop the subscript $t$ ). From Theorem 1, the optimal contract can be implemented

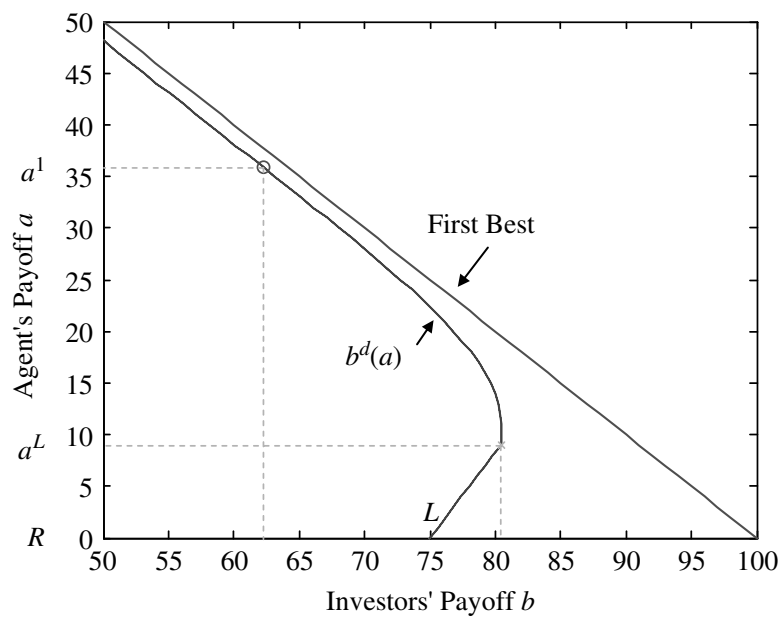

Figure 5

Optimal continuation function for the example

This figure shows the investor's continuation function for the example with $T \rightarrow \infty$. For an agent continuation payoff $a>a^{1}=35.83, b^{d}(a)$ is linear with slope -1 , reflecting the optimality of paying the agent $a-a^{1}$ in cash. For an agent continuation payoff $a<a^{L}=9.05, b^{d}(a)$ is also linear, reflecting the optimality of randomizing between termination payoffs $\left(L_{t}, R_{t}\right)$ which equals $(75,0)$, and $\left(b^{d}\left(a^{L}\right), a^{L}\right)$ which equals $(80.52,9.05)$. For $a^{L} \leq a \leq a^{1}$, there are no cash payments to the agent and the termination probability is 0 . 
with long-term debt with perpetual coupons of

$$
x=\mu+\lambda^{-1}\left[a^{1}-e^{\gamma\left(t-t^{-}\right)} a^{1}\right]=10+[35.83-1.105 \times 35.83]=6.24
$$

together with a credit line with an annual interest rate of $10.5 \%$ and credit limit of

$$
c^{L}=\lambda^{-1}\left(a^{1}-a^{L}\right)=35.83-9.05=26.78
$$

By issuing the long-term debt without drawing on the credit line, the agent is initially able to raise $b^{d}\left(a^{1}\right)=62.30$. The agent will raise this amount of capital if $I \leq 62.30$, and consume any cash not invested. If $I>62.30$, an initial draw on the credit line is required to fund the project. By drawing the credit line to its limit, the agent can raise a maximum of $b^{d}\left(a^{L}\right)=80.52$ from investors. Because of the incentive problem, if $80.52<I \leq 100$, the project cannot be financed even though it has a positive NPV. ${ }^{18}$

We illustrate the contract for a sample cash flow history in Table 1, for the case $I \leqslant 62.30$ in which there is no initial draw on the credit line.

Table 1

An Illustration of the Optimal Contract for a Sample Cash Flow Realization

\begin{tabular}{lrrrrrrrr} 
Period & \multicolumn{1}{c}{1} & \multicolumn{1}{c}{3} & \multicolumn{1}{c}{4} & \multicolumn{1}{c}{5} & 6 & \multicolumn{1}{c}{7} & \multicolumn{1}{c}{8} \\
\hline Credit line (begin) & 0.00 & 0.00 & -1.37 & 0.00 & -6.90 & -14.51 & -20.72 & -29.59 \\
Cash flow Y & 10.00 & 5.00 & 8.00 & 0.00 & 0.00 & 2.00 & 0.00 & 0.00 \\
LT debt coupon $x$ & -6.24 & -6.24 & -6.24 & -6.24 & -6.24 & -6.24 & -6.24 & -6.24 \\
\hline Current assets - Liab. & 3.76 & -1.24 & 0.39 & -6.24 & -13.14 & -18.75 & -26.96 & -35.83 \\
Dividend paid $d$ & -3.76 & & -0.39 & & & & 0.18 & 9.05 \\
Default amount $z$ & & & & & & & $2.0 \%$ & $100 \%$ \\
Term. probability $p$ & & & & & & & -18.75 & -26.78 \\
Credit line (end) & 0.00 & -1.24 & 0.00 & -6.24 & -13.14 & -18 \\
\hline
\end{tabular}

The agent draws on the credit line when the cash flow is less than the coupon payment (periods 2 and 4-8) and pays a dividend when the credit line is repaid (periods 1 and 3). If the agent exceeds his credit line limit (periods 7 and 8), then the firm may be terminated.

If the cash flow is less than the coupon payment on the debt, as in period 2, the agent draws on the credit line. The credit line balance accrues interest at a rate of $10.5 \%$. The agent pays down any existing balance on the credit line using the firm's cash flows net of coupon payments. If the credit line is fully repaid, as in periods 1 and 3, any excess cash flow is paid as a dividend. If the credit line balance exceeds the credit limit, as in

18 The additional capital raised by drawing $c^{L}=26.78$ from the credit line is only $80.52-62.30=18.22$. The difference is due to the fact that by drawing on the credit line, the likelihood of default increases, reducing the value of the debt. 
periods 7 and 8 , the firm defaults on the excess amount $z$. In that event, the contract is terminated based on a notional equity value of ${ }^{19}$

$$
N=\lambda^{-1}\left(a^{L}-R\right)=9.05-0=9.05
$$

Starting with a zero draw on the credit line, the agent's expected utility from the dividends under the above contract is $a^{1}=35.8$. The debt coupon is set so that this amount is equivalent to the perpetuity value of the expected dividend that the agent earns when the credit line is repaid:

$$
(10-6.24) / 0.105=35.8
$$

The fact that incentive compatibility constraints bind implies that this amount also equals the agent's expected payoff from immediately drawing the credit line to its limit, diverting the entire cash flow in the next period, and defaulting:

$$
26.78+10 / 1.105=35.8
$$

Note also that, as shown in period 8 of the example, reporting a 0 cash flow once the credit line is at its limit leads to a $100 \%$ probability of termination.

Given a zero draw on the credit line, the combined value of the firm to the agent and investors is $35.8+62.3=98.1$. Thus, the inefficiency caused by the agency problem reduces the agent's utility by $100-98.1=1.9$. This loss is due to the delay in the payments to the agent, plus the possibility of inefficient termination of the project.

The example above focused on the infinite horizon steady-state for simplicity. With a finite horizon, the debt payment and credit limit decrease as we get close to the project horizon, $T$. Figure 6 illustrates the debt and credit limit based on the project's remaining life for an example in which the assets, if liquidated, generate observable cash flows of 7.5 per period, so that $L_{t}$ is the present value of this annuity (consistent with a steady-state liquidation value of 75). Starting from the steady-state values, the credit limit falls to zero, and the debt matures, by the final period (specifically, $x_{T^{*}}=0$ and $c_{T^{*-}}^{L}=c_{T^{*}}^{L}=0$ ).

\subsection{Special cases and comparative statics}

To understand better the role of each security, we consider some special cases. First, we show that the level of long-term debt depends on the agent's impatience. If $\gamma=r$, the long-term debt is used solely to borrow against the project's observable (minimum) cash flows, $Y_{t}^{0}$.

${ }^{19}$ For this choice of parameters, commitment to the contract is necessary, as both the agent and investors would prefer to renegotiate termination. As we will show in Section 4.1.3, commitment is not needed for an optimal contract if the assets have a liquidation value $L_{t} \geq 84$. Alternatively, without commitment one could calculate the optimal renegotiation-proof contract in a finite horizon setting using the techniques of Section 2.9. 


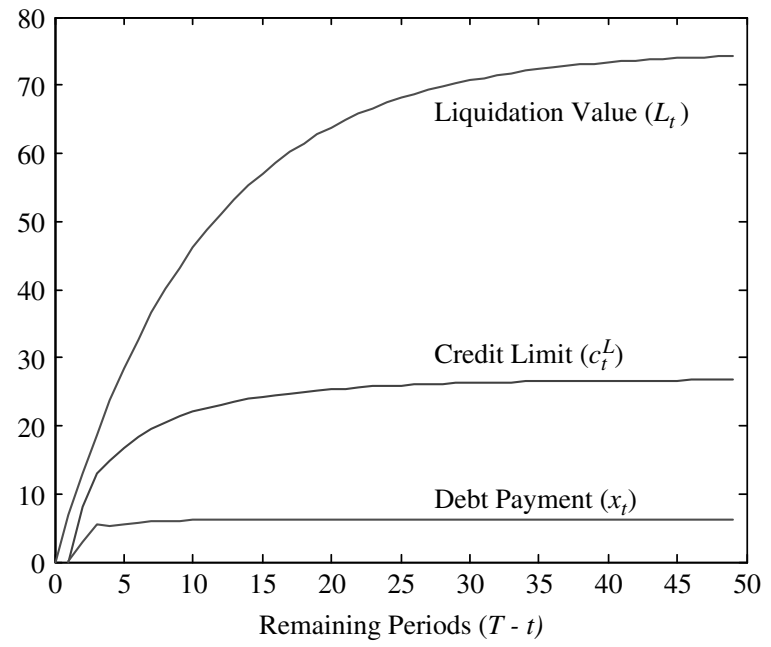

Figure 6

Credit limit and debt payments with a finite horizon

As the remaining project life declines, the credit limit, $c_{t}^{L}$, and the debt payment, $x_{t}$, shrink to 0 . For this example, the liquidation value $L_{t}$ equals the present value of 7.5 per period for the remaining project life.

Theorem 2. Suppose the agent's outside option does not bind at the dividend boundary, $R_{t^{-}}<a_{t^{-}}^{1}$. Then

(i) If $\gamma=r$, then $x_{t}=Y_{t}^{0}$ for all $0<t \leq T$.

(ii) If $\gamma>r$, then $x_{t} \geq Y_{t}^{0}$.

If the agent's discount rate matches the investors' $(\gamma=r)$, then once the credit line is paid off, there is no longer any possibility of default - the cash flow exceeds the required debt payment $\left(Y_{t} \geq x_{t}=Y_{t}^{0}\right)$, and the firm uses the excess cash flow $\left(Y_{t}-Y_{t}^{0}\right)$ to pay a dividend each period from then on. Because there is no benefit to early consumption, the agent does not consume until the chance of default is eliminated. Once the credit line is repaid, the contract achieves the first-best payoff and the agent receives the fraction $\lambda$ of the firm's unverifiable cash flows (or his outside option). In this case the dividend boundary is straightforward to compute:

Corollary 3. If $\gamma=r$, then $a_{t}^{1}+b_{t}^{e}\left(a_{t}^{1}\right)=V_{t}^{F B}$, and $a_{t}^{1}$ can be calculated according to

$$
a_{t}^{1}=\sum_{s=t^{+}}^{T} e^{-r(s-t)} \lambda\left(\mu_{s}-Y_{s}^{0}\right)+e^{-r(T-t)} R_{T} .
$$

In contrast, if the agent is impatient $(\gamma>r)$ then the required long-term debt payments will generally exceed $Y_{t}^{0}$. Thus, even if the credit line is fully 
repaid, the firm may face the risk of a cash shortfall $\left(Y_{t}<x_{t}\right)$ that requires it to draw on the credit line. The higher level of long-term debt in this case increases the risk of default, but benefits the agent by providing additional consumption at the start of the project.

Also note that when $\gamma>r$, it is possible that $T^{*}<T$. That is, it may be optimal to terminate the project earlier than its first-best life. For example, if $\lambda=1$ and $Y_{t}^{0}=0$, then as $\gamma \rightarrow \infty, T^{*} \rightarrow 0$ and the project terminates immediately. The intuition is that it is impossible for investors to induce payment from an extremely impatient agent, so investors will enforce early termination.

In Theorem 2 we assume that the agent's outside option, $R_{t^{-}}$is not too high. If the agent's outside option is sufficiently high, it may be necessary to delay his compensation to keep him from quitting early. In terms of our implementation, the subsequent period's debt payment $x_{t}$ is reduced (and may fall below $Y_{t}^{0}$ ), making continuation more attractive to the agent.

Figure 7 illustrates these results in the context of our infinite-horizon example. If the agent's discount rate equals the market interest rate, $\gamma=r=10 \%$, then the optimal long-term debt coupon is zero, so only the credit line is used, and no cash is taken out of the firm in the initial financing. Once the credit line is paid off, the agent is debt-free and the project will never be terminated. But if the agent is impatient $(\gamma>r)$, it is optimal to use risky long-term debt. This debt will fund an initial cash payout, but also implies that the firm will eventually default and the contract will be terminated. The inefficiency that results from eventual termination diminishes the maximum investment that can be financed. Figure 7 shows this maximum initial capital that can be financed, as well as the initial capital that can be financed with no initial draw on the credit line. The difference between these two capital amounts is less than the firm's available credit due to the lower credit quality of the firm if it draws on the credit line initially. Note that the optimal debt structure is extremely fragile at $\gamma=r$; if the agent is even slightly impatient relative to investors, substantial long-term debt will be used.

The prior results provide insight into the role of the long-term debt. Next we show that the role of the credit line is to provide financial slack given the uncertainty and potential growth of the cash flows. Indeed, if the cash flows of the project were constant, the credit line would not be needed:

Theorem 3. Suppose that renegotiation is not possible (or the constraint does not bind) and $\gamma>r$. Then the optimal credit limit converges to zero, $c_{t}^{L} \rightarrow 0$, as the volatility of the cash flows goes to zero as long as the expected cash flows do not grow too quickly, $\mu_{t^{+}}-Y_{t^{+}}^{0} \leq e^{\gamma\left(t^{+}-t\right)}\left(\mu_{t}-Y_{t}^{0}\right)$ for all $0<t<T^{*}$.

The above result requires that expected cash flows do not grow too quickly. Otherwise an optimal contract may provide some financial slack 


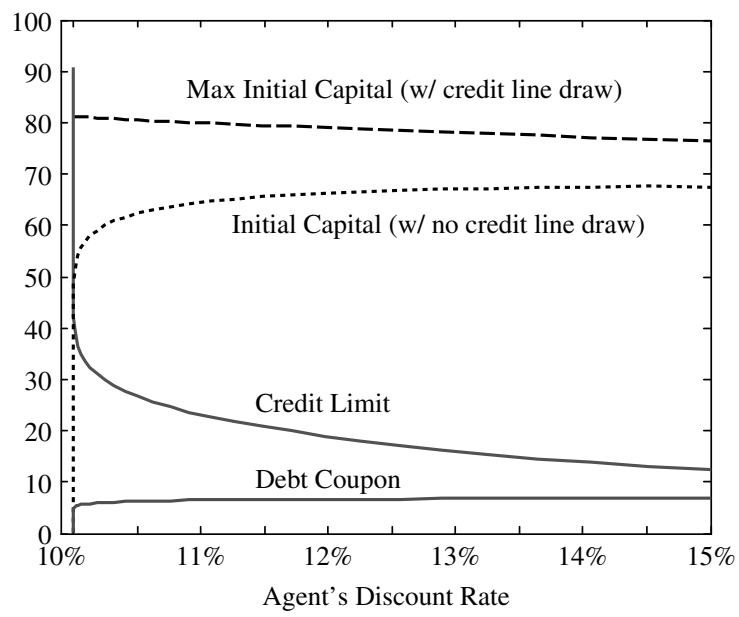

Figure 7

Effect of the agent's discount rate $\gamma$ on the optimal contract

If the agent and investors have the same discount rate, $\gamma=r$ (in this example $r=10 \%$ ), there is no long-term debt. As $\gamma$ increases, the debt coupon increases and the limit on the credit line decreases. The maximum amount of initial capital (i.e., debt capacity since there is no outside equity in this example) decreases in $\gamma$.

in earlier periods because the threat of termination in later periods will be sufficient to provide incentives.

Figure 8 illustrates the optimal contract as a function of cash flow volatility for our infinite-horizon example. ${ }^{20}$ Because of the possibility of default and termination, higher volatility projects entail greater contracting costs. So while the credit limit increases with risk (providing more financial slack), the long-term debt and maximum investment decreases.

Figure 9 illustrates the effect of the termination value of the assets, $L_{t}$, on the optimal contract. An increase in $L_{t}$ increases the amount of external financing the firm can raise, as well as its reliance on long-term debt. In contrast, the limit on the credit line is reduced. The intuition for this result is that an increase in the liquidation value of the assets reduces the inefficiency of termination, and so reduces the need for financial slack.

The homogeneity of the model implies that increasing the termination payoffs and the project cash flows proportionally will have the same proportional effect on the optimal contract. Combining this fact with the result from Figure 9, we can deduce the effect of increasing the project's cash flows on the optimal contract. For example, consider doubling the project's cash flows without increasing the assets' termination value.

${ }^{20}$ Here we let the probability of cash flow $y$ be proportional to $\exp \left(k(y-\mu)^{2}\right)$, where $k$ ranges from $-\infty$ ( $Y_{t}$ is riskless) to $\infty$ ( $Y_{t}$ is binary with outcomes 0 or 20$)$. Uniform corresponds to $k=0$. We depict the outcomes as a function of the standard deviation of the cash flows. 


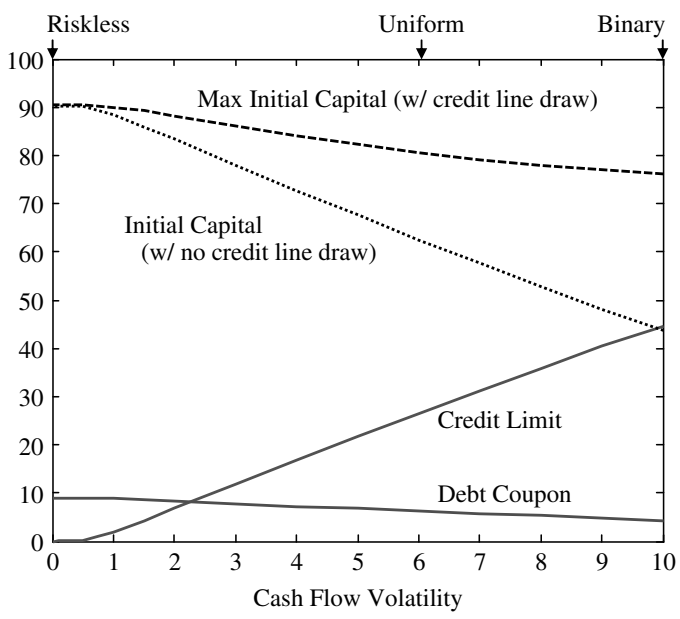

\section{Figure 8}

\section{Effect of cash flow volatility on the optimal contract}

If the cash flow is riskless, the line of credit is not used. As cash flow volatility increases, the debt coupon decreases and the limit on the credit line increases. The maximum amount of initial capital (debt capacity) decreases in cash flow volatility.

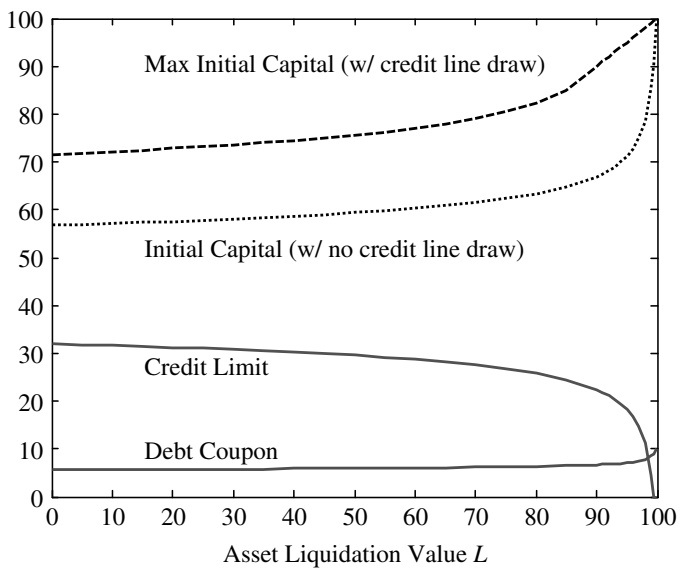

\section{Figure 9}

Effect of the asset termination/liquidation value $L$ on the optimal contract

As the asset liquidation value $L$ increases, the long-term debt coupon increases and the limit on the credit line decreases. The maximum amount of initial capital (debt capacity) increases in the liquidation value.

Because we have increased the relative inefficiency of termination, the optimal contract will have a greater relative reliance on the credit line; that is, such a change will more than double the credit limit, and will increase the long-term debt coupons by a factor of less than two. A similar result 
would hold if the project's cash flows were increased by a constant - the debt coupons would increase by less than the increase in the cash flows.

From Theorem 1, the agent's ability to divert the cash flows, parameterized by $\lambda$, directly determines the optimal fraction of outside equity, $1-\lambda$. The indirect effect of $\lambda$ on the optimal debt structure of the firm can be understood from the following result:

Theorem 4. The optimal long-term debt and credit limit with $\lambda<1$ and termination payoffs $\left(R_{t}, L_{t}\right)$ is equal to the optimal long-term debt and credit limit with $\lambda=1$ and termination payoffs:

$$
R_{t}^{\prime}=R_{t} / \lambda \text {, and } L_{t}^{\prime}=L_{t}-\frac{1-\lambda}{\lambda}\left(V_{t}^{F B}-L_{t}\right) .
$$

Thus, when $R_{t}=0$ as in our example, decreasing $\lambda$ has the same effect on the optimal debt structure as decreasing the assets' termination value - and so from Figure 9 leads to a higher credit limit and lower long-term debt. For example, with $R_{t}=0$ and $V_{t}^{F B}=100$, (19) implies that reducing $\lambda$ from 1.00 to .25 leads to the same debt structure as lowering $L_{t}$ from 75 to 0 . Our model therefore predicts a positive correlation between outside equity and financial slack. Intuitively, a reduction in agency costs (lower $\lambda$ ) reduces the share of the equity the agent needs to hold to provide adequate incentives, and also makes continuing the project more attractive (relative to terminating), increasing the need for financial slack.

\section{Termination Payoffs}

In this section we discuss how different specifications for the termination payoffs $\left(R_{t}, L_{t}\right)$ correspond to different applications of our model. Depending on the application, $\left(R_{t}, L_{t}\right)$ may be exogenous or endogenous.

\subsection{The asset liquidation value}

One obvious interpretation for $L_{t}$ is as a liquidation value based on the value of the assets in some alternative use. If the alternative use generates observable cash flows with expected value $v_{t}$ in period $t$, then

$$
L_{t}=\sum_{s>t} e^{-r(s-t)} v_{s} .
$$

That is, when the project is terminated, the assets are sold for their value in the alternative use.

4.1.1 Ongoing investment. Another interpretation of the formulation in (20) is that the business requires ongoing investment. That is, suppose 
that an initial investment $\nu_{0}$ is required to start the firm, and that each period, an investment of $v_{t}$ is required to keep the firm in operation. Then

$$
I=v_{0}+L_{0}
$$

is the initial capital investors must set aside to finance the future operations. In any period $t$, however, investors can "pull the plug" and terminate the contract, and in this way recover $L_{t} \cdot{ }^{21}$

4.1.2 Monitoring. The formulation in (20) can also be interpreted as a monitoring technology that can be introduced to monitor the firm's cash flows and eliminate the agency problem. Monitoring is costly, reducing the expected cash flow in period $t$ from $\mu_{t}$ to $v_{t}$. In this case, termination means introducing the monitoring technology, making the business worth $L_{t}$. Thus, the optimal contract determines the circumstances under which the monitoring technology is installed. Prior to its installation, investors use the threat of monitoring to provide incentives to the agent.

4.1.3 Investors can hire a new agent. In the above cases, the liquidation value is exogenous. Now consider an application with an endogenous liquidation value $L_{t}$. Suppose that upon termination, investors fire the current agent and hire a new equivalent agent. Assume the pool of available new agents is competitive, and that a dismissed agent receives a reservation utility $R_{t}=0$. This scenario reflects a case in which the assets are unique in some way but that there are substitutes for the agent. When hiring a new agent, investors can offer the agent the contract that yields the highest possible continuation utility for investors. Therefore, the payoff to the investors when the contract with the current agent is terminated is

$$
L_{t}=\max _{a} b_{t}^{e}(a) .
$$

Under this specification, termination is always renegotiation-proof, and we have the following further characterization of the parameters in the optimal contract:

Proposition 6. Suppose $R_{t}=0$ and $L_{t}$ is given by (22) for all $t$. Then the optimal contract with commitment is also renegotiation-proof and satisfies

$$
a_{t}^{L}=e^{-\gamma\left(t^{+}-t\right)} \lambda\left(\mu_{t^{+}}-Y_{t^{+}}^{0}\right), L_{t}=b_{t}^{e}\left(a_{t}^{L}\right) \text { and } l_{t}=0 .
$$

In addition, the optimal debt and credit line terms are independent of $\lambda$.

So as the severity of the agency problem varies - that is, $\lambda$ varies, the terms of the debt contracts are unchanged. The only changes involve

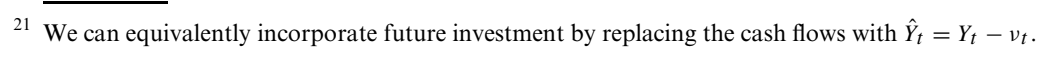




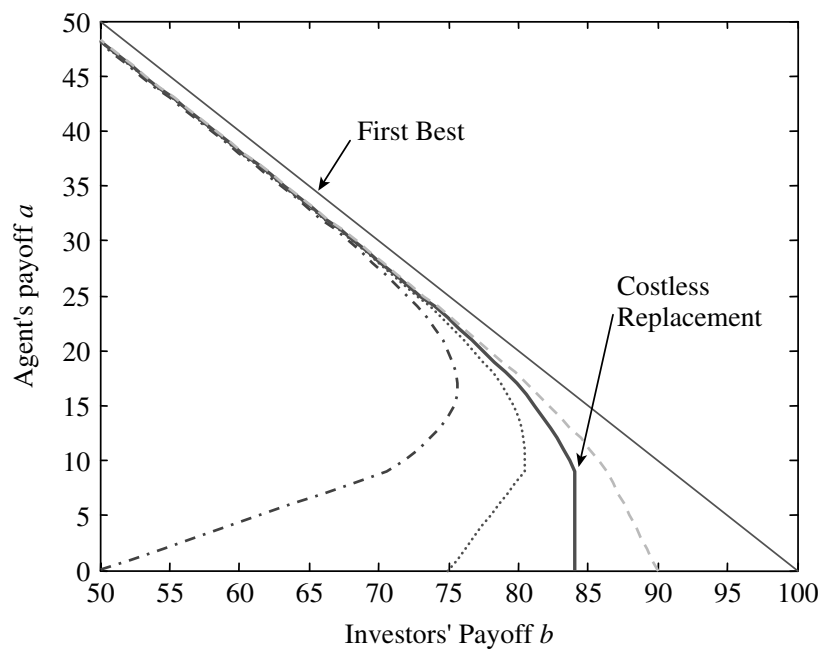

Figure 10

Computing the optimal contract when the agent can be costlessly replaced

This figure illustrates the continuation function for different values of $L_{t}$. The endogenous liquidation value that applies when the agent can be costlessly replaced is the solution to (22).

the fraction of equity held by the agent and the amount of funding that investors will provide (i.e., the pricing of the debt and equity).

While replacing the agent entails no efficiency loss, the new agent captures rents equal to $a_{t}^{L}$, the present value of diverting next period's unverifiable cash flow. As a result the prospect of termination reduces the payoffs available to the initial agent and the investors. ${ }^{22}$

We can compute the optimal continuation function for this setting numerically by adjusting the termination payoff $L_{t}$ until (22) holds. We illustrate the solution for the infinite-horizon example of Section 3.2 in Figure 10. In that case, the ability to replace the agent is equivalent to a liquidation payoff of $L_{t}=84$. The (steady-state) debt coupon is 6.45, and the credit limit is 24.77 . At termination, the current agent is fired, and a new agent hired. The new agent is given a contract with initial value $a_{t}^{L}=9.05=10 / 1.105$, which implies a payoff of $L_{t}=b_{t}^{e}\left(a_{t}^{L}\right)=84$.

Note that the debt coupon is higher, and the credit limit is lower, than for the earlier example in which we assumed $L_{t}=75$. Because firing and replacing the agent is more efficient than liquidating the assets, the optimal contract provides less financial flexibility.

Here we assumed that an agent can always be replaced with an equivalent agent who can manage the project. In other settings with scarce managerial talent, it may be optimal to reinstate a previously terminated agent.

\footnotetext{
${ }^{22}$ See Spear and Wang (2005) for an optimal contracting model of firing and replacing a risk-averse agent.
} 
However, Gromb (1999) shows that in a stationary environment with renegotiation and no replacement agents, it is not optimal to temporarily lay off an agent and "mothball" the assets, starting up again in the future. Rather, it is optimal for termination to specify a permanent severing of the relationship.

Variations on the above can be considered. For example, each period investors may have the option of either replacing or monitoring the agent. In that case,

$$
L_{t}=\max \left(\max _{a} b_{t}^{e}(a), e^{-r\left(t^{+}-t\right)}\left(v_{t^{+}}+L_{t^{+}}\right)\right) .
$$

Another variation is to suppose that there are costs associated with hiring a new agent. Let $\Delta_{t}^{a}$ and $\Delta_{t}^{b}$ represent the switching cost of the new agent and the investors, respectively. Then

$$
L_{t}=\max _{a} b_{t}^{e}(a)-\Delta_{t}^{b} \text { s.t. } a \geq \Delta_{t}^{a},
$$

where the constraint $a \geq \Delta_{t}^{a}$ is required to induce the new agent to participate.

Finally, if there are no switching costs and new agents have sufficient access to capital, there is an obvious solution - rent the assets to an agent each period, with rent equal to the value of next period's unverifiable cash flow. Specifically, our optimal contract reduces to $c_{t}^{L}=0$ and $x_{t}=Y_{t}^{0}+e^{-\gamma\left(t^{+}-t\right)}\left(\mu_{t^{+}}-Y_{t^{+}}^{0}\right)$; by forcing the agent to pay for the cash flows in advance, the agency problem is essentially eliminated.

\subsection{The agent's reservation value}

Now we turn our attention to alternative specifications of $R_{t}$. In the simplest case, the agent can be employed in another activity with expected wage $\eta_{s}$ in period $s$. Then,

$$
R_{t}=\sum_{s>t} e^{-\gamma(s-t)} \eta_{s}
$$

4.2.1 Sovereign lending. Consider the Bulow and Rogoff (1989) model. A consortium of banks (the investors) lend to an LDC (the agent). The LDC generates export revenues $Y_{t}$ that can be used to repay the banks. If the LDC defaults, the banks can seize a fraction $\beta$ of the exports, keeping a fraction $\alpha \leq \beta$ after allowing for deadweight costs associated with seizure. Thus, we can use (20) and (25), letting $\eta_{t}=(1-\beta) \mu_{t}$ and $v_{t}=\alpha \mu_{t}$, and solve for the optimal contract in that setting.

Generally, we would suppose $\eta_{t}+v_{t} \leq \mu_{t}$ (seizure is costly). But even if $\eta_{t}+v_{t} \geq \mu_{t}$, termination is not necessarily efficient if $\gamma>r$, as the agent would prefer to receive cash up front rather than receive $\eta_{t}$ over time. However, the next result shows that when the level of production in 
termination is sufficiently high, the optimal contract involves immediate termination, and the agent is unable to borrow against future income.

Proposition 7. Suppose (20) and (25) hold and

$$
\eta_{t}+v_{t} \geq \mu_{t}+\left(1-e^{(\gamma-r)\left(t-t^{-}\right)}\right)\left(v_{t}-\left[Y_{t}^{0}+(1-\lambda)\left(\mu_{t}-Y_{t}^{0}\right)\right]\right) \text { for all } t .
$$

Then it is optimal to terminate the project immediately. Thus, the agent's initial borrowing capacity is $L_{0}$.

4.2.2 Agent can start a new business. Now consider a case in which $R_{t}$ is determined endogenously. Suppose the agent's human capital is the scarce resource, and the physical assets are replaceable. In this case, $L_{t}$ corresponds to the liquidation/replacement value of the assets. If the project is terminated, the agent loses control of the existing assets but can start a new firm. To do so, the agent must raise $L_{t}$ from investors to replace the assets. This can be modeled as

$$
R_{t}=\max \left\{a: b_{t}^{e}(a) \geq L_{t}\right\} \cup\left\{e^{-\gamma\left(t^{+}-t\right)} R_{t^{+}}\right\} .
$$

That is, the agent earns the highest payoff consistent with being able to purchase new assets by borrowing $L_{t}$ from new investors. If the agent cannot finance a new project this period, the agent waits until next period to attempt financing. In this case, the agent's ability to start a new firm substitutes for renegotiation - that is,

Proposition 8. Suppose $R_{t}$ is given by (26) for all $t$. Then the optimal contract with commitment is also renegotiation-proof.

This model is closely related to Hart (1995; Chapter 5). There, however, cash flows are deterministic so that $Y_{t}=\mu_{t}$. Hart's emphasis is on the "inalienability of human capital," or the agent's right to quit. Here we model that by assuming the agent can quit and start a new firm if new capital can be raised to purchase equivalent assets for price $L_{t}$ (this is equivalent to Hart's assumption regarding the agent's bargaining power). The difference between our model and Hart's is the following. We assume that asset purchases are observable, so if the agent quits and starts a new firm in period $s$, the entire amount $L_{s}$ must be financed externally. Funds contributed by the agent could be seized by creditors of the initial firm. Hart's specification is equivalent to assuming that the agent can contribute previously diverted capital to start the new firm.

This is best illustrated by example. Suppose $Y_{t}=\mu_{t}=10$ (deterministic cash flows), $\lambda=1$ (no deadweight diversion cost), $v_{t}=6$ (the periodic cash flow generated by the best alternative use of assets - this determines the liquidation values), $T=3, r=0$, and $\gamma$ is very close to zero but positive (the assumption on $\gamma$ selects Hart's "slowest" repayment policy). Since 
Table 2

Comparison with Hart (1995)

\begin{tabular}{|c|c|c|c|c|}
\hline$t$ & 0 & 1 & 2 & 3 \\
\hline$Y_{t}$ & & 10 & 10 & 10 \\
\hline$L_{t}$ & 18 & 12 & 6 & 0 \\
\hline$x_{t}$ & & 8 & 10 & 0 \\
\hline Hart 95 & & 6 & 6 & 0 \\
\hline
\end{tabular}

Consider a riskless project with periodic cash flows of 10 and liquidation value declining by 6 per period. In our model the agent's debt capacity is 18. In Hart's model, debt capacity is 12 due to his assumption that the agent can use diverted funds to start a new firm.

$\lambda=1$, by Theorem 1 the agent retains all of the equity, and since there is no uncertainty, by Theorem 3 the credit line is zero. Table 2 calculates the optimal long-term debt payment, $x_{t}$, from our analysis as well as the optimal payments from Hart (1995).

To fund the project initially, the agent must invest 18 to buy the assets. In our model, the agent can finance the full investment. In Hart (1995), the agent can finance at most 12 .

To understand the difference, consider the payment in period 2. In our model the agent will pay $x_{2}=10$ because the agent is threatened with losing the project, which is worth 10 in period 3. This result differs from Hart (1995), who assumes that the agent can divert cash from the current project and use it to fund a new firm. In that case, the agent will never pay out more than the current value of the assets - so in period 2, the agent will pay out at most 6 . In our model the agent cannot start a new firm using diverted funds because the creditors of the initial firm would seize the new firm's assets.

Working backward in our model, in period 1 the agent is also unable to quit and raise 12 to start a new firm since he can promise to repay at most 10. Thus, the threat of termination in period 1 could induce the agent to pay up to 10 . However, $x_{1}+x_{2}$ cannot exceed 18 since otherwise in period 0 the agent would quit and start a new firm by raising 18 and promising to repay $8+10$ to a creditor. In Hart's model, the agent will again pay no more than 6 in period 1. Otherwise he could quit, and use cash of 6 diverted from the current project and the promise to repay 6 in period 2 to start a new firm.

Thus, the critical difference between our models concerns whether the initial creditors can seize cash that is diverted and invested in the assets of a new firm. In our analysis they can, and so creditors have more power than in Hart's framework, and our contract leads to superior outcomes. (In addition, relative to Hart (1995), our model generalizes to the case of uncertain cash flows and different discount rates.) 
4.2.3 Agent finances a sequence of projects. Another variant of our model subsumes the model of Gromb (1999) in which participation of both the investors and the agent is necessary (no party has an outside option). There is a sequence of positive NPV projects. The project in period $t$ requires investment $v_{t}$ and produces cash flow $Y_{t}$. (Gromb restricts this further by assuming stationarity and $Y_{t}$ binary.) Each period a decision must be made whether to finance the current project or to "mothball" and remain idle.

Absent renegotiation, Gromb's model coincides with that discussed in (20)-(21) above, since investors can commit to permanent liquidation and refuse to finance any future projects (which Gromb shows is optimal). With renegotiation, this environment can be modeled with $L_{t}$ as in (23), and

$$
R_{t}= \begin{cases}a_{t}^{*} & \text { if } b_{t}^{e}\left(a_{t}^{*}\right)>e^{-r\left(t^{+}-t\right)}\left(v_{t^{+}}+L_{t^{+}}\right) \\ e^{-\gamma\left(t^{+}-t\right)} R_{t^{+}} & \text {otherwise }\end{cases}
$$

where $a_{t}^{*}=\arg \max _{a} b_{t}^{e}(a)$. That is, investors get the highest possible continuation payoff with the agent employed, or they mothball and recover $v_{t}$. Correspondingly, the agent earns rents only when the project is not mothballed.

4.2.4 Renegotiation procedures. In our analysis, the possibility of renegotiation constrains the contract by requiring that it always be Pareto efficient. In contrast, renegotiation in Bulow and Rogoff (1989); Hart (1995) and Hart and Moore (1998) is modeled as a procedure that is exogenously imposed on the contracting problem. For example, Bulow and Rogoff assume that renegotiation means that the agents play an alternating offer bargaining game. One could accommodate this view of renegotiation by specifying $\left(R_{t}, L_{t}\right)$ to be the payoffs from the particular bargaining game selected-so for instance, in period $t$, the agent can "quit," and invoke the period- $t$ bargaining game.

\section{Asset Substitution and Hidden Effort}

Thus far, we have taken the distribution of the cash flows $Y_{t}$ to be exogenous. But there may be a moral hazard component to these cash flows. In this section we consider briefly some consequences of unobserved investment decisions by the agent.

\subsection{Asset substitution (risk shifting)}

Consider a pure form of the asset-substitution problem: the agent can influence the riskiness of future cash flows, but not their mean. Specifically, suppose in period $s$, the agent can choose a parameter $\phi_{s}$ that does not affect the mean of the future cash flows and leaves $Y_{t}^{0}$ as a lower bound on 
the support of the cash flow distribution,

$$
E\left[Y_{t} \mid \phi_{s}\right]=E\left[Y_{t}\right]=\mu_{t} \text { and } \operatorname{Pr}\left(Y_{t} \geq Y_{t}^{0} \mid \phi_{s}\right)=1
$$

but does affect other moments of the cash flow distribution; for example, $\operatorname{Var}\left(Y_{t} \mid \phi_{s}\right)$ may vary with $\phi_{s}$.

In standard models of risky debt, equity holders have an incentive to increase the riskiness of the cash flows as this transfers wealth from the debt holders (see Jensen and Meckling (1976)). However, even though long-term debt and the credit line are risky in our model, there is no asset-substitution problem under the optimal financial contract:

Proposition 9. Under the optimal contract of Section 2, the agent is indifferent to the choice of the pure asset substitution parameter $\phi_{s}$ satisfying (27). The agent can therefore be assumed to choose $\phi_{s}$ optimally for investors and eliminate any mean-preserving spreads. Thus, the contract of Section 2 remains optimal.

The intuition is as follows. Increasing risk generally benefits equity holders because of the convexity of their claim - they participate more in the gains than in the losses. In our model, incentive compatibility requires that the agent pay for losses through the possibility of termination. So while the agent's period- $t$ cash payoff is convex in the period- $t$ cash flow, the agent's period- $t$ total payoff, cash plus continuation utility, is linear in the period- $t$ cash flow. Thus there is no gain for the agent from increasing risk. There would be a loss for the debt holders, however, since their payoff function $b_{t}^{d}$ is concave in the cash flows (due to the deadweight costs associated with termination).

\subsection{Hidden agent effort}

Consider next unobserved agent effort. Suppose the agent can expend effort $\operatorname{cost} \varepsilon_{s} \in \xi_{s}$ in period $s$, where $\varepsilon_{s}$ is denominated in consumptionequivalent units and we assume $0 \in \xi_{s}$. Suppose this effort affects current output $Y_{s}$, but not future output. We assume that effort leads to higher output so that $\varepsilon_{s}$ increases $Y_{s}$ in the sense of First Order Stochastic Dominance (FOSD).

Because the agent's payoff under our optimal contract in period $s$ is

$$
a_{s}^{d}=a_{s}^{y}+\lambda\left(Y_{s}-\mu_{s}\right)-\varepsilon_{s},
$$

the agent chooses $\varepsilon_{s}^{*}$ to solve

$$
\max _{\varepsilon \in \xi_{s}} \lambda E\left[Y_{s} \mid \varepsilon_{s}=\varepsilon\right]-\varepsilon .
$$


Under certain conditions, the contract derived in this article remains optimal in the case of hidden effort. We discuss two important scenarios below.

5.2.1 Hidden effort and hidden cash flows. Suppose the agent can divert cash at rate $\lambda$ as well as make a hidden effort choice. If $\lambda$ is close to one, the agent's incentives for effort provision under our contract are close to first best. If the solution to (28) involves maximal effort, the optimal contract is unchanged by the addition of hidden effort:

Proposition 10. Suppose $\lambda$ is sufficiently high that the solution $\varepsilon_{s}^{*}$ to (28) is such that $\varepsilon_{s}^{*}=\max \left\{\varepsilon \in \xi_{s}\right\}$. Then the optimal contract with hidden effort and hidden cash flows is the contract of Section 2 with $\mu_{s}=E\left[Y_{s} \mid \varepsilon_{s}^{*}\right]$ and agent termination value $R_{t}+\sum_{s>t} e^{-\gamma(s-t)} \varepsilon_{s}^{*}$.

This case is likely to occur when the effort choice is binary. As long as $\lambda$ is sufficiently high to motivate high effort, the contract is optimal. ${ }^{23}$ See Shim (2006) for an application of this model to banking regulation.

5.2.2 Hidden effort and public binary cash flows. Suppose the only agency problem arises from hidden effort and cash flows are observable and take on only two values. Effort affects the likelihood of a high versus low cash flow. In this case, in many circumstances our contract is also the optimal principal-agent contract to implement a given level of effort. The intuition for the result is that with binary cash flows, the agent's payoff must be linear in the cash flows. Thus this agency problem is equivalent to ours with a particular $\lambda$.

For simplicity, let the agency problem be stationary so that $\xi_{s}$ and $E\left[Y_{s} \mid \varepsilon_{s}=\varepsilon\right]$ do not depend on $s$. Let $\lambda^{*}(\varepsilon)$ be the minimal $\lambda$ such that the solution to (28) is $\varepsilon^{*}=\varepsilon$. Then we have the following result:

Proposition 11. The optimal principal-agent contract that implements effort level $\varepsilon$ is the contract of Section 2 with $\lambda=\lambda^{*}(\varepsilon), \mu_{s}=E\left[Y_{s} \mid \varepsilon\right]$ and agent termination value $R_{t}+\sum_{s>t}\left\{e^{-\gamma(s-t)} \varepsilon\right\}$.

For example, suppose the effort choice is binary. Let $\varepsilon \in\left\{\varepsilon_{h}, \varepsilon_{l}\right\}$ and $\Delta \varepsilon=\varepsilon_{h}-\varepsilon_{l}$. Let $\Delta \mu=E\left[Y_{s} \mid \varepsilon_{h}\right]-E\left[Y_{s} \mid \varepsilon_{l}\right]$ for all $s$. Then the optimal

23 The reason we require effort to be maximal, as opposed to just efficient (i.e., solving $(28)$ for $\lambda=1$ ), is that with privately observed cash flows it may be optimal to induce higher than first-best effort in order to avoid the deadweight cost of termination. Optimal effort exceeds the first-best if effort increases output in the sense of FOSD, and if the first-best effort is interior. On the other hand, if effort also increases risk, then it is possible that optimal effort is below the first-best level. Povel and Raith (2004) examine this model with a binary effort choice and consider cases in which (i) first-best effort is low effort; and (ii) high effort entails higher risk as well as higher return. 
principal-agent contract that implements high effort is equivalent to our contract with ${ }^{24}$

$$
\lambda=\lambda^{*}\left(\varepsilon_{h}\right)=\Delta \varepsilon / \Delta \mu .
$$

Finally, note that the above analysis considered effort that affects current output. If effort also affects future output, then the contract of Section 2 no longer induces the first-best effort level. There are two reasons for this. First, the agent discounts future cash flows at rate $\gamma \geq r$. Second, in general there is a positive probability that the agent will be terminated prior to receiving the benefit of the effort.

\section{Concluding Remarks}

Our analysis establishes that in the presence of the incentive problems associated with privately observed cash flows, standard securities can implement an optimal long-term financial contract. We have a theory of long-term debt combined with outside equity.

Static capital structure "tradeoff" models generally predict a positive relation between earnings and leverage. But empirical attempts to find such a relation have been largely unsuccessful, casting doubt on such models. Our dynamic model suggests a more subtle relation between earnings and leverage, where expected earnings and realized earnings have opposing effects. Our model predicts that other things equal, firms with higher expected earnings will carry more debt. However, firms will optimally use earnings to pay down debt. Hence, other things equal, firms with higher realized earnings will carry less debt. Thus, leverage ratios will be strongly history dependent.

As an example of the evolution of a firm's optimal capital structure, reconsider the example from Section 3.2, dividing a period into 100 sub-periods with sub-periodic cash flow $Y_{t} \in\{-0.9,1.1\}$, where the two outcomes are equally likely. ${ }^{25}$ The securities are priced (ex dividend) by discounting the expected future payments at the rate $r$. This corresponds to pricing all of the equity at the market price (since the agent discounts cash flows at rate $\gamma>r$, the agent places a lower value on his nontraded shares).

Figure 11 illustrates two sample paths for a firm's capital structure (in market values) given different cash flow realizations. With low cash flows, the firm accumulates debt (and approaches default). With high cash flows, the firm pays down its debt. In this example, the firm begins

\footnotetext{
${ }^{24}$ There is a remaining issue regarding whether it is optimal to implement the same effort level every period. In the binary effort setting this is the case if low effort is sufficiently unproductive. See the working paper version of Biais et al. (2007) and DeMarzo and Sannikov (2006) for more on this point.

25 This corresponds to an annual expected cash flow of 10 with a volatility of 10 . For this case, the optimal financial structure entails perpetual debt with annual coupons totaling 3.88 . The credit line has a limit of 60.25 and an interest rate of $10.5 \%$. The notional value of the equity is 1 .
} 
paying dividends when the debt-value ratio falls to $39 \%$. As shown, a firm's capital structure is highly dependent on its history. Also, as shown, a firm's capital structure can vary substantially over time even though the firm's cash flow distribution is not changing. Two firms with the same cash flow distribution and termination payoffs might have very different capital structures depending on their histories. More generally, Theorem 1 establishes how capital structure dynamics depend on the distribution of cash flows (past and future) as well as their history.

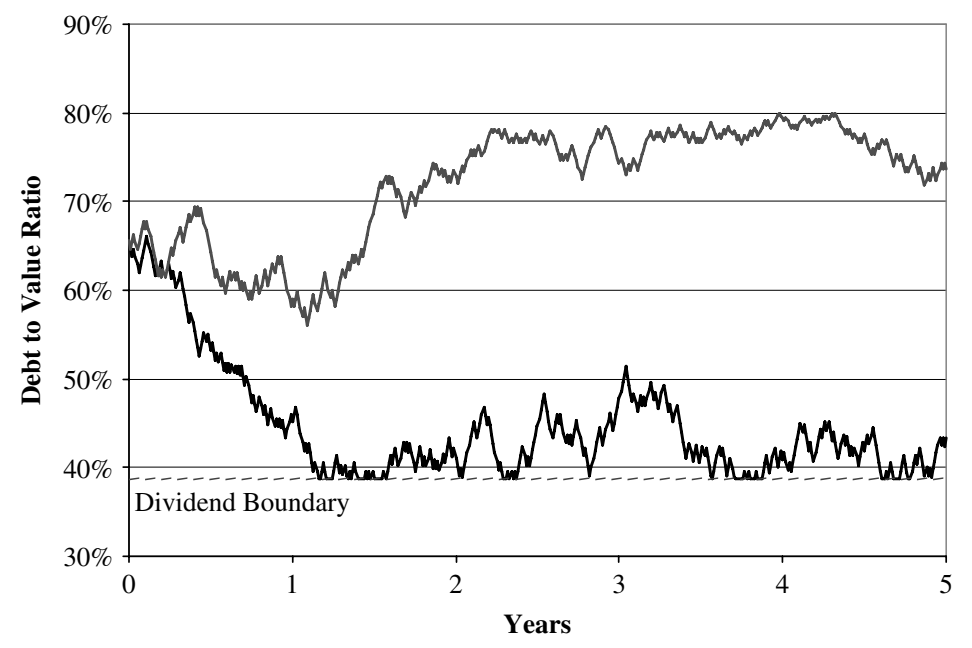

Figure 11

Possible sample paths for the firm's optimal leverage ratio

A firm's optimal capital structure is history dependent. If the firm has low cash flows, it optimally accumulates debt (the higher path); and if the firm has high cash flows, it optimally pays down its debt (the lower path). Once the debt is sufficiently low (in this example, a 39\% debt-value ratio), the firm begins paying dividends.

We assumed that the business is run at a fixed scale. Albuquerque and Hopenhayn (2004); Quadrini (2004); Clementi and Hopenhayn (2006), and DeMarzo and Fishman (2007) consider dynamic models in which the scale of the business is determined as part of the optimal contract. These models generate implications regarding the relation between investment decisions, past profits, leverage and dividend payouts, and firm size and age. Among the implications, controlling for the profitability of current investment, the optimal contract entails more current investment if current and past profits are high. Also, investment will be positively serially correlated over time. Like the threat of termination, the promise of funding for new investment can improve an agent's incentives.

In our model, the cash flows over time are independent. This simplifies matters by leading to symmetric information regarding future payoff 
possibilities even if the agent diverts a cash flow (and thus misleads investors regarding the current cash flow). An important generalization is to allow for correlated cash flows. Tchistyi (2006) adapts our model to the case of cash flows that follow a binary Markov switching process. $\mathrm{He}$ characterizes the optimal contract and shows that it can be implemented using a credit line whose interest rate increases with the amount of borrowing.

When we considered renegotiation-proof contracts, we assumed that renegotiation is costless. However, perhaps another important distinction between types of securities is the cost of renegotiating. If so, an interesting issue is whether there is an optimal implementation that relaxes the renegotiation constraint. For instance, it may be easier for the agent to renegotiate with the bank that issued the credit line than with dispersed debt or equity holders. In this case, it may be optimal to make the credit line senior in the event of default so as to increase the incentives for the bank to follow through with a threat of termination.

In our model, the agent does not consume unless dividends are paid. It would be straightforward to add a constraint that the agent be paid some fixed amount each period: we can reinterpret the cash flows as net of the fixed amount. Even better would be to introduce agent risk aversion. Then the optimal contract would need to provide both incentives and consumption smoothing. It would also be interesting to embed this model in a general equilibrium environment and consider the effect of productivity shocks on the dynamics of aggregate output.

\section{Appendix:}

Proof of Proposition 1. This is standard, and follows the argument in the text.

Proof of Proposition 2. The construction of $b_{t}^{d}$ follows as in Figure 2. First, consider the termination option $\left(L_{t}, R_{t}\right)$. Since the agent can always terminate and receive $R_{t}$, payoffs below this are infeasible: $b_{t}^{d}(a)=-\infty$ for $a<R_{t}$. For payoffs above $R_{t}$, we need to find the line from $\left(L_{t}, R_{t}\right)$ to the curve $b_{t}^{e}$ with highest slope. This highest slope is given by $l_{t}$. If $l_{t}>-1$, then the line with the highest slope connects to $b_{t}^{e}$ at $a_{t}^{L}$. Thus, payoffs $a_{t}^{d} \in\left[R_{t}, a_{t}^{L}\right]$ are provided by mixing between termination and continuing with $a_{t}^{L}$. The probability of termination is given by $p_{t}$ in (4), which solves $p_{t} R_{t}+\left(1-p_{t}\right) a_{t}^{L}=a_{t}^{d}$. In this case the investors' expected payoff is

$$
p_{t} L_{t}+\left(1-p_{t}\right) b_{t}^{e}\left(a_{t}^{L}\right)=b_{t}^{e}\left(a_{t}^{L}\right)+\frac{a_{t}^{L}-a_{t}^{d}}{a_{t}^{L}-R_{t}}\left(L_{t}-b_{t}^{e}\left(a_{t}^{L}\right)\right)=b_{t}^{e}\left(a_{t}^{L}\right)-l_{t}\left(a_{t}^{L}-a_{t}^{d}\right) .
$$

Since $l_{t}>-1$, there is $a_{t}^{1} \geq a_{t}^{L}$ such that in the region $\left[R_{t}, a_{t}^{1}\right]$ it is cheaper to compensate the agent by reducing the termination probability rather than paying him directly. Above $a_{t}^{1}$, it is cheaper to compensate the agent directly with the payment $d_{t}$ given by (5). In this case the investors' payoff is

$$
b_{t}^{d}\left(a_{t}^{d}\right)=b_{t}^{e}\left(a_{t}^{1}\right)-d_{t}=b_{t}^{e}\left(a_{t}^{1}\right)-\left(a_{t}^{d}-a_{t}^{1}\right)
$$


Finally, suppose that $l_{t} \leq-1$. In this case, paying the agent directly is cheaper for any payoff above $R_{t}$. Thus, it is optimal to terminate with probability 1 (which is equivalent to $a_{t}^{L}=\infty$ in the definition of $p_{t}$ ), and the investors' payoff is

$$
b_{t}^{d}\left(a_{t}^{d}\right)=L_{t}-d_{t}=L_{t}-\left(a_{t}^{d}-R_{t}\right)
$$

for $a_{t}^{d} \geq R_{t}=a_{t}^{1}$.

Proof of Proposition 3. Here we need to solve the optimization problem (7). For completeness, we begin by verifying that it is without loss of generality to assume that the agent pays the entire cash flow $Y_{t}$ at the solution (although this is already shown in Proposition 1). Suppose there is a solution in which the agent pays $\hat{y}_{t}\left(Y_{t}\right) \leq Y_{t}$ and receives $a_{t}^{d}\left(\hat{y}_{t}\right)$. Consider the new reward schedule $a_{t}^{d *}\left(Y_{t}\right)=a_{t}^{d}\left(\hat{y}_{t}\left(Y_{t}\right)\right)+\lambda\left(Y_{t}-\hat{y}_{t}\left(Y_{t}\right)\right)$. Given this reward schedule, it is easy to see that truthful reporting is optimal, and the agent's payoffs are unchanged. The change in the investors' payoff is given by

$$
\begin{aligned}
{\left[Y_{t}+b_{t}^{d}\left(a_{t}^{d *}\left(Y_{t}\right)\right)\right] } & -\left[\hat{y}_{t}+b_{t}^{d}\left(a_{t}^{d}\left(\hat{y}_{t}\right)\right)\right] \\
& =Y_{t}-\hat{y}_{t}+b_{t}^{d}\left(a_{t}^{d}\left(\hat{y}_{t}\right)+\lambda\left(Y_{t}-\hat{y}_{t}\right)\right)-b_{t}^{d}\left(a_{t}^{d}\left(\hat{y}_{t}\right)\right) \\
& \geq 0
\end{aligned}
$$

where the last inequality follows since $b_{t}^{d^{\prime}}(a) \geq-1$ and $\lambda \leq 1$.

Given truthful reporting, the (IC) constraint is equivalent to $g(y) \equiv a_{t}^{d}(y)-\lambda y$ weakly increasing. The constraint (PK) then becomes $E\left[g\left(Y_{t}\right)\right]=a_{t}^{y}-\lambda \mu_{t}$, and the investors' payoff is

$$
E\left[Y_{t}+b_{t}^{d}\left(\lambda Y_{t}+g\left(Y_{t}\right)\right)\right]=\mu_{t}+E\left[b_{t}^{d}\left(\lambda Y_{t}+g\left(Y_{t}\right)\right)\right] .
$$

Since the mean of $g$ is fixed by (PK), and since $b_{t}^{d}$ is concave, the optimal choice of $g$ is to minimize the risk of $\lambda Y_{t}+g\left(Y_{t}\right)$ subject to the constraint that $g$ is weakly increasing. This is satisfied by making $g$ constant. Thus, $a_{t}^{d}(y)=\lambda y+g(y)=a_{t}^{y}+\lambda\left(y-\mu_{t}\right)$. Finally, since expectation is a positive linear operator, the concavity of $b_{t}^{y}$ follows from the concavity of $b_{t}^{d}$.

Proof of Proposition 4. Follows immediately given the discount rates of the agent and the investors.

Proof of Proposition 5. Renegotiation-proofness of a continuation function $b$ is equivalent to $b^{\prime}(a) \leq 0$ whenever $b(a)>-\infty$. Note first that $b_{T}^{e \prime}<0$. Note also that $b_{t}^{d \prime} \leq 0$ implies that $b_{t}^{y \prime} \leq 0$ and hence that $b_{t^{-}}^{e \prime} \leq 0$. Thus, the only stage at which renegotiation-proofness can be violated is the construction of $b_{t}^{d}$ from $b_{t}^{e}$. Since $b_{t}^{e \prime} \leq 0$, the violation occurs only if $l_{t}>0$. In that case, the definition of $a_{t}^{L}$ in Proposition 2 is equivalent to $a_{t}^{L}=\inf \left\{a>R_{t}: b_{t}^{e}(a)>-\infty\right\}$. Since termination is infeasible, renegotiation-proofness is equivalent to the requirement that when $l_{t}>0, b_{t}^{d}(a)=-\infty$ for $a<a_{t}^{L}$.

Proof of Theorem 1: First we show that standard securities replicate the optimal mechanism given the agent's strategy and then we show that the agent's strategy is incentive compatible.

Step 1-Replication:

First we claim that given a credit line position of

$$
c_{t}^{d}=\lambda^{-1}\left(a_{t}^{1}-a_{t}^{d}\right)
$$

in the middle of period $t$, the future outcomes are identical to the optimal mechanism given the agent has the feasible continuation payoff $a_{t}^{d}$ (i.e., $a_{t}^{d} \geq R_{t}$, or $a_{t}^{d} \geq a_{t}^{L}$ in the case of a renegotiation-proof contract when termination is inefficient). 
Note that if the credit line balance is negative - that is, if there is excess cash after paying all liabilities - then that cash will be used to pay a dividend. Thus, the agent's payment is

$$
d_{t}=\lambda \max \left(-c_{t}^{d}, 0\right)=\max \left(a_{t}^{d}-a_{t}^{1}, 0\right)
$$

If $t=T^{*}$, the project is then terminated and the proceeds $L_{t}$ are claimed by the debt holders. If $t<T^{*}$, then default occurs if the credit line is overdrawn, and the project is terminated with probability

$$
\begin{aligned}
p_{t} & =\frac{\max \left(c_{t}^{d}-c_{t}^{L}, 0\right)}{N_{t}}=\frac{\max \left(\lambda^{-1}\left(a_{t}^{1}-a_{t}^{d}\right)-\lambda^{-1}\left(a_{t}^{1}-a_{t}^{L}\right), 0\right)}{\lambda^{-1}\left(a_{t}^{L}-R_{t}\right)} \\
& =\frac{\max \left(a_{t}^{L}-a_{t}^{d}, 0\right)}{\left(a_{t}^{L}-R_{t}\right)}
\end{aligned}
$$

otherwise the overdraft is forgiven. Thus, the ending balance on the credit line is given by

$$
\begin{aligned}
c_{t}^{e} & =\max \left(\min \left(c_{t}^{d}, c_{t}^{L}\right), 0\right)=\lambda^{-1} \max \left(\min \left(a_{t}^{1}-a_{t}^{d}, a_{t}^{1}-a_{t}^{L}\right), 0\right) \\
& =\lambda^{-1}\left(a_{t}^{1}-\min \left(\max \left(a_{t}^{d}, a_{t}^{L}\right), a_{t}^{1}\right)\right) \\
& =\lambda^{-1}\left(a_{t}^{1}-a_{t}^{e}\right)
\end{aligned}
$$

In the following period, the credit line accrues interest at rate $\gamma$. In addition, the debt coupon $x_{t}$ must be paid, and cash flows $Y_{t}$ are received and can be used to pay down the credit line. This leads to a new balance of

$$
\begin{aligned}
c_{t^{+}}^{d} & =e^{\gamma\left(t^{+}-t\right)} c_{t}^{e}+x_{t^{+}}-Y_{t^{+}} \\
& =e^{\gamma\left(t^{+}-t\right)} \lambda^{-1}\left(a_{t}^{1}-a_{t}^{e}\right)+\mu_{t^{+}}+\lambda^{-1}\left(a_{t^{+}}^{1}-e^{\gamma\left(t^{+}-t\right)} a_{t}^{1}\right)-Y_{t^{+}} \\
& =\lambda^{-1}\left[a_{t^{+}}^{1}-\left(e^{\gamma\left(t^{+}-t\right)} a_{t}^{e}+\lambda\left(Y_{t^{+}}-\mu_{t^{+}}\right)\right)\right] \\
& =\lambda^{-1}\left(a_{t^{+}}^{1}-a_{t^{+}}^{d}\right)
\end{aligned}
$$

Finally, note that since $a_{t}^{d}$ is feasible, we know from the optimal mechanism that $a_{t^{+}}^{d}$ is feasible as well.

Step 2-Incentive Compatibility:

For each $\$ 1$ paid as a dividend, the agent retains $\lambda$. Thus, there is no incentive for the agent to divert funds in lieu of a dividend. Similarly, for each $\$ 1$ paid on the credit line, the agent's continuation payoff grows by $\lambda$, and so again there is no incentive to divert, nor is there an incentive to pay a dividend rather than pay off the credit line. (Note that if the agent draws on the credit line in excess of current liabilities, even if the credit line is at its limit at the end of period $t$, this corresponds to the feasible continuation payoff $a_{t}^{L}$.)

Next consider termination. At the conclusion of any period $t<T^{*}$, the agent's continuation payoff is at least $R_{t}$ (by feasibility), so there is no incentive to terminate early. At the end of period $T^{*}$, if the agent terminates, he receives $R_{T^{*}}$. Thus the total opportunity cost for the agent to pay off the final debt claim of $L_{T^{*}}$ rather than terminate, is $R_{T^{*}}+\lambda L_{T^{*}}$. For continuation to be preferred to termination, the agent must earn a continuation payoff that exceeds this amount:

$$
a_{T^{*}}^{e}>R_{T^{*}}+\lambda L_{T^{*}} .
$$


The payoff $a_{T^{*}}^{e}$ is the present value of the agent's share of future dividends, which we denote by $\eta$, plus some ultimate termination payoff:

$$
a_{T^{*}}^{e}=\eta+E\left[e^{-\gamma\left(\tau-T^{*}\right)} R_{\tau}\right] .
$$

Now, investors receive fraction $(1-\lambda)$ of the dividends, so that

$$
b_{T^{*}}^{e}\left(a_{T^{*}}^{e}\right) \geqslant \frac{1-\lambda}{\lambda} \eta \text {. }
$$

Also, from (1),

$$
R_{T^{*}} \geq E\left[e^{-\gamma\left(\tau-T^{*}\right)} R_{\tau}\right]
$$

Combining (A1)-(A4), we get

$$
\begin{aligned}
a_{T^{*}}^{e}+b_{T^{*}}^{e}\left(a_{T^{*}}^{e}\right) & \geq \frac{1}{\lambda} \eta+E\left[e^{-\gamma\left(\tau-T^{*}\right)} R_{\tau}\right] \\
& >\frac{1}{\lambda}\left[R_{T^{*}}-E\left[e^{-\gamma\left(\tau-T^{*}\right)} R_{\tau}\right]+\lambda L_{T^{*}}\right]+E\left[e^{-\gamma\left(\tau-T^{*}\right)} R_{\tau}\right] \\
& \geq R_{T^{*}}+L_{T^{*}}
\end{aligned}
$$

But this contradicts the fact that $l_{T^{*}} \leq-1$. Thus, termination in period $T^{*}$ is optimal for the agent.

Proof of Theorem 2: Note that since $b^{d}$ is concave,

$$
\begin{aligned}
b_{t^{-}}^{e \prime}\left(a_{t^{-}}^{e}\right) & =e^{(\gamma-r)\left(t-t^{-}\right)} b_{t}^{y \prime}\left(e^{\gamma\left(t-t^{-}\right)} a_{t^{-}}^{e}\right) \\
& =e^{(\gamma-r)\left(t-t^{-}\right)} E\left[b_{t}^{d \prime}\left(e^{\gamma\left(t-t^{-}\right)} a_{t^{-}}^{e}+\lambda\left(Y_{t}-\mu_{t}\right)\right)\right] \\
& \leq e^{(\gamma-r)\left(t-t^{-}\right)} b_{t}^{d^{\prime}}\left(e^{\gamma\left(t-t^{-}\right)} a_{t^{-}}^{e}+\lambda\left(Y_{t}^{0}-\mu_{t}\right)\right)
\end{aligned}
$$

Since $b_{t}^{d \prime}(a)=-1$ for $a \geq a_{t}^{1}$, this implies that

$$
\left.b_{t^{-}}^{e \prime}\left(a_{t^{-}}^{e}\right) \leq-1 \text { if (and only if, when } \gamma=r\right) a_{t^{-}}^{e} \geq e^{-\gamma\left(t-t^{-}\right)}\left[a_{t}^{1}+\lambda\left(\mu_{t}-Y_{t}^{0}\right)\right]
$$

This implies that

$$
a_{t^{-}}^{1} \leq e^{-\gamma\left(t-t^{-}\right)}\left[a_{t}^{1}+\lambda\left(\mu_{t}-Y_{t}^{0}\right)\right]
$$

unless $R_{t^{-}}$binds, in which case

$$
a_{t^{-}}^{1}=a_{t^{-}}^{L}=R_{t^{-}}>e^{-\gamma\left(t-t^{-}\right)} a_{t}^{1}+\lambda\left(\mu_{t}-Y_{t}^{0}\right) .
$$

Rearranging (A5) and using the definition of $x_{t}$ yields $x_{t} \geq Y_{t}^{0}$, with equality when $\gamma=r$. Note that this also implies that when $\gamma=r$,

$$
a_{t^{-}}^{1}=\max \left(R_{t^{-}}, e^{-r\left(t-t^{-}\right)}\left[a_{t}^{1}+\lambda\left(\mu_{t}-Y_{t}^{0}\right)\right]\right),
$$

allowing for an easy recursive calculation of $a_{t}^{1}$ for this case. Note also that this implies that if $a_{t^{-}}^{d} \geq a_{t^{-}}^{1}$, then $a_{t}^{d} \geq a_{t}^{1} \geq a_{t}^{L}$. Thus, once the agent has continuation payoff above 
$a_{t}^{1}$, early termination will not occur. This implies that the payoffs are first best-i.e., $b_{t}^{d}\left(a_{t}^{1}\right)+a_{t}^{1}=V_{t}^{F B}$. Thus $T^{*}=T$, and Corollary 3 is also established.

Proof of Theorem 3. Note that $c_{T^{*}}^{L}=0$ by definition. Define

$$
a_{t}^{0} \equiv e^{-\gamma\left(t^{+}-t\right)}\left[R_{t^{+}}+\lambda\left(\mu_{t^{+}}-Y_{t^{+}}^{0}\right)\right]
$$

the minimum feasible continuation payoff at the end of period $t$ absent renegotiation in period $t^{+}$. Now, for $t=T^{*-}$, note that since $b_{T^{*}}^{d^{\prime}}(a)=-1$, then $b_{t}^{e \prime}\left(a_{t}^{0}\right) \leq-1$. This implies that

$$
a_{t}^{1}=a_{t}^{L}=\max \left(R_{t}, a_{t}^{0}\right), \text { and so } c_{t}^{L}=0 .
$$

We now show that this holds inductively for $t^{-}$. First, note that

$$
\begin{aligned}
b_{t^{-}}^{e \prime}\left(a_{t^{-}}^{0}\right) & =e^{(\gamma-r)\left(t-t^{-}\right)} b_{t}^{y \prime}\left(e^{\gamma\left(t-t^{-}\right)} a_{t^{-}}^{0}\right) \\
& =e^{(\gamma-r)\left(t-t^{-}\right)} E\left[b_{t}^{d \prime}\left(R_{t}+\lambda\left(Y_{t}-Y_{t}^{0}\right)\right)\right] \\
& \approx e^{(\gamma-r)\left(t-t^{-}\right)} b_{t}^{d \prime}\left(R_{t}+\lambda\left(\mu_{t}-Y_{t}^{0}\right)\right)
\end{aligned}
$$

where the last equation holds given a degenerate distribution for $Y_{t}$. Thus, if $R_{t}+\lambda\left(\mu_{t}-Y_{t}^{0}\right) \geq a_{t}^{1}$, then we have that $b_{t^{-}}^{e \prime}\left(a_{t^{-}}^{0}\right) \leq-1$, which implies (A7) in period $t^{-}$. Indeed, rather than $Y_{t}$ degenerate, this only requires

$$
\operatorname{Pr}\left(Y_{t} \geq \mu_{t}\right) \geq \frac{e^{(r-\gamma)\left(t-t^{-}\right)}+b_{t}^{d^{\prime}}\left(R_{t}\right)^{+}}{1+b_{t}^{d \prime}\left(R_{t}\right)^{+}}
$$

So, it remains to establish

$$
R_{t}+\lambda\left(\mu_{t}-Y_{t}^{0}\right) \geq a_{t}^{1}=\max \left(R_{t}, a_{t}^{0}\right)
$$

which is implied by

$$
R_{t}+\lambda\left(\mu_{t}-Y_{t}^{0}\right) \geq a_{t}^{0}=e^{-\gamma\left(t^{+}-t\right)}\left[R_{t^{+}}+\lambda\left(\mu_{t^{+}}-Y_{t^{+}}^{0}\right)\right]
$$

Since $R_{t} \geq e^{-\gamma\left(t^{+}-t\right)} R_{t}+$ from (1), it is enough that

$$
\left(\mu_{t}-Y_{t}^{0}\right) \geq e^{-\gamma\left(t^{+}-t\right)}\left(\mu_{t^{+}}-Y_{t^{+}}^{0}\right) .
$$

Note also that when $R_{t}=0$ for all $t$,

$$
\begin{aligned}
x_{t} & =\mu_{t}+\lambda^{-1}\left[a_{t}^{1}-e^{\gamma\left(t-t^{-}\right)} a_{t^{-}}^{1}\right]=\mu_{t}+\lambda^{-1}\left[a_{t}^{0}-e^{\gamma\left(t-t^{-}\right)} a_{t^{-}}^{0}\right] \\
& =\mu_{t}+e^{-\gamma\left(t^{+}-t\right)}\left(\mu_{t^{+}}-Y_{t^{+}}^{0}\right)-\left(\mu_{t}-Y_{t}^{0}\right) \\
& =Y_{t}^{0}+e^{-\gamma\left(t^{+}-t\right)}\left(\mu_{t^{+}}-Y_{t^{+}}^{0}\right)
\end{aligned}
$$

Proof of Theorem 4: Let $b_{t}^{d, \lambda}$ be the optimal continuation function given diversion rate $\lambda<1$ and termination payoffs $\left(R_{t}, L_{t}\right)$, and let $b_{t}^{d}$ be the optimal continuation payoff with diversion rate $\lambda=1$ and termination payoffs $\left(R_{t}^{\prime}, L_{t}^{\prime}\right)$. We prove this result by showing that

$$
b_{t}^{d, \lambda}\left(a_{t}^{d}\right)=\lambda b_{t}^{d}\left(\lambda^{-1} a_{t}^{d}\right)+(1-\lambda) V_{t}^{F B}
$$


and in addition that $a_{t}^{1, \lambda}=\lambda a_{t}^{1}$ and $a_{t}^{L, \lambda}=\lambda a_{t}^{L}$. Note that for final date $T$,

$$
b_{T}^{d, \lambda}(a)=L_{T}+R_{T}-a=\lambda\left(L_{T}^{\prime}+R_{T}^{\prime}-\lambda^{-1} a\right)+(1-\lambda) V_{t}^{F B}
$$

so that (A8) holds. We now show that it holds inductively. Supposing it holds for $b_{t}^{d, \lambda}$ implies that

$$
\begin{aligned}
b_{t}^{y, \lambda}\left(a_{t}^{y}\right) & =\mu_{t}+E\left[b_{t}^{d, \lambda}\left(a_{t}^{y}+\lambda\left(Y_{t}-\mu_{t}\right)\right)\right] \\
& =\lambda\left(\mu_{t}+E\left[b_{t}^{d}\left(\lambda^{-1} a_{t}^{y}+\left(Y_{t}-\mu_{t}\right)\right)\right]\right)+(1-\lambda)\left(\mu_{t}+V_{t}^{F B}\right) \\
& =\lambda b_{t}^{y}\left(\lambda^{-1} a_{t}^{y}\right)+(1-\lambda)\left(\mu_{t}+V_{t}^{F B}\right)
\end{aligned}
$$

Therefore,

$$
\begin{aligned}
b_{t^{-}}^{e, \lambda}\left(a_{t^{-}}^{e}\right) & =e^{-r\left(t-t^{-}\right)} b_{t}^{y, \lambda}\left(e^{\gamma\left(t-t^{-}\right)} a_{t^{-}}^{e}\right) \\
& =\lambda e^{-r\left(t-t^{-}\right)} b_{t}^{y}\left(\lambda^{-1} e^{\gamma\left(t-t^{-}\right)} a_{t^{-}}^{e}\right)+(1-\lambda) e^{-r\left(t-t^{-}\right)}\left(\mu_{t}+V_{t}^{F B}\right) \\
& =\lambda b_{t^{-}}^{e}\left(\lambda^{-1} a_{t^{-}}^{e}\right)+(1-\lambda) V_{t^{-}}^{F B}
\end{aligned}
$$

Thus, $b_{t^{-}}^{e, \lambda}(a)=b_{t^{-}}^{e \prime}\left(\lambda^{-1} a\right)$, which implies that $a_{t}^{1, \lambda}=\lambda a_{t}^{1}$ and, given $l_{t}, a_{t}^{L, \lambda}=\lambda a_{t}^{L}$. Finally, $l_{t}$ is unchanged since

$$
\begin{aligned}
\frac{b_{t^{-}}^{e, \lambda}\left(a_{t^{-}}^{L, \lambda}\right)-L_{t^{-}}}{a_{t^{-}}^{L, \lambda}-R_{t^{-}}} & =\frac{\lambda b_{t^{-}}^{e}\left(a_{t^{-}}^{L}\right)+(1-\lambda) V_{t^{-}}^{F B}-\left(\lambda L_{t^{-}}^{\prime}+(1-\lambda) V_{t^{-}}^{F B}\right)}{\lambda a_{t^{-}}^{L}-\lambda R_{t^{-}}^{\prime}} \\
& =\frac{b_{t^{-}}^{e}\left(a_{t^{-}}^{L}\right)-L_{t^{-}}^{\prime}}{a_{t^{-}}^{L}-R_{t^{-}}^{\prime}}
\end{aligned}
$$

Finally, applying the construction in Proposition 2 yields the result for $b_{t^{-}}^{d, \lambda}$.

Proof of Proposition 6. That $L_{t}=b_{t}^{e}\left(a_{t}^{L}\right)$ and $l_{t}=0$ follows immediately from (22). Since $l_{t} \geq 0$ for all $t, b_{t}^{d \prime} \geq 0$ as well and so the optimal contract is renegotiation proof. Thus, (22) is satisfied for the smallest feasible $a: a_{t}^{L}=\inf \left\{a: b_{t}^{e}(a)>-\infty\right\}$. The minimal continuation payoff at the end of period $t$ is the one that is just feasible after the worst possible reported cash flow next period:

$$
e^{\gamma\left(t^{+}-t\right)} a_{t}^{L}+\lambda\left(Y_{t^{+}}^{0}-\mu_{t^{+}}\right)=R_{t^{+}} .
$$

Since $R_{t}=0$ for all $t$, we get the indicated expression for $a_{t}^{L}$.

Finally, the conditions of Theorem 4 are satisfied since $R_{t}=0$ and at $T, L_{T}=L_{T}^{\prime}=$ $V_{T}^{F B}=0$. Using the induction argument from the proof of Theorem 4, this implies that at $T^{-}$,

$$
b_{T^{-}}^{e, \lambda}\left(a_{T^{-}}^{e}\right)=\lambda b_{T^{-}}^{e}\left(\lambda^{-1} a_{T^{-}}^{e}\right)+(1-\lambda) V_{T^{-}}^{F B}
$$

Therefore, $L_{T^{-}}=\lambda L_{T^{-}}^{\prime}+(1-\lambda) V_{T^{-}}^{F B}$. This argument can be repeated to verify (19) for each $t$.

Proof of Proposition 7: Let $t=T^{*-}$. From the proof of Theorem 3, $b_{t}^{e \prime}\left(a_{t}^{0}\right) \leqslant-1$ where $a_{t}^{0}$ is given by (A6). Thus, termination is not optimal in period $t$ if and only if

$$
L_{t}+R_{t}<\max _{a}\left(a+b_{t}^{e}(a)\right)=a_{t}^{0}+b_{t}^{e}\left(a_{t}^{0}\right) .
$$


Since $b_{t}^{e}\left(a_{t}^{0}\right)=e^{-r\left(T^{*}-t\right)}\left(L_{T^{*}}+Y_{T^{*}}^{0}+(1-\lambda)\left(\mu_{T^{*}}-Y_{T^{*}}^{0}\right)\right)$, using (20) and (25) the above can be rewritten as

$$
\eta_{T^{*}}+v_{T^{*}}<\mu_{T^{*}}+\left(1-e^{(\gamma-r)\left(T^{*}-t\right)}\right)\left(v_{T^{*}}-\left[Y_{T^{*}}^{0}+(1-\lambda)\left(\mu_{T^{*}}-Y_{T^{*}}^{0}\right)\right]\right)
$$

Thus, if this is not satisfied for all $T^{*}>0$, immediate termination is optimal.

Proof of Proposition 8: If the commitment contract is not renegotiation-proof, it must be that $l_{t}>0$ for some $t$. This implies that $a_{t}^{L} \geq R_{t}$ and $b_{t}^{e}\left(a_{t}^{L}\right)>L_{t}$. By continuity, this implies there exists $a>R_{t}$ such that $b_{t}^{e}(a) \geq L_{t}$, contradicting (26).

Proof of Proposition 9: From the analysis in Section 2, the agent's continuation payoff $a_{t}^{d}=a_{t}^{y}+\lambda\left(Y_{t}-\mu_{t}\right)$. Thus, the agent's expected continuation payoff is unaffected by $\phi_{s}$. On the other hand, $b_{t}^{y}\left(a_{t}^{y}\right)=\mu_{t}+E\left[b_{t}^{d}\left(a_{t}^{y}+\lambda\left(Y_{t}-\mu_{t}\right)\right)\right]$ and $b_{t}^{d}$ is concave. Thus, investors prefer that $\phi_{s}$ be chosen to eliminate mean-preserving spreads.

Proof of Proposition 10: From the proof of Proposition 3 the incentive compatibility constraint implies that the agent's payoff as a function of $Y_{t}$ is given by $\lambda Y_{t}+g_{t}\left(Y_{t}\right)$ for some weakly increasing function $g_{t}$. Given such a payoff, by FOSD and the fact that $\varepsilon_{s}^{*}=\max \left\{\varepsilon \in \xi_{s}\right\}$ solves (28), the agent will choose effort $\varepsilon_{s}^{*}$ under any incentive-compatible contract. Thus, we can regard this effort choice as exogenous and solve for the optimal contract as in the previous analysis. Since the payoffs are computed gross of effort costs, we adjust the agent's termination payoff equivalently (in other words, in the event of termination, the agent saves the future effort costs in addition to receiving $R_{t}$ ).

Proof of Proposition 11: With binary cash flows $\left(Y_{t} \in\left\{Y_{t}^{0}, Y_{t}^{0}+\Delta Y_{t}\right\}\right)$, conditional on a history an optimal contract specifies some continuation payoff $a_{l}$ after a low cash flow and $a_{h}=a_{l}+\Delta a$ after a high cash flow. Let $\pi_{t}(\varepsilon)$ be the probability of a high cash flow given effort $\varepsilon$. By hypothesis, $\varepsilon$ is a solution to

$$
\max _{\varepsilon^{\prime}} \pi_{t}\left(\varepsilon^{\prime}\right) \lambda \Delta Y_{t}-\varepsilon^{\prime}
$$

for $\lambda=\lambda^{*}(\varepsilon)$, and is not a solution for $\lambda<\lambda^{*}(\varepsilon)$. Since the agent chooses effort to solve

$$
\max _{\varepsilon^{\prime}} \pi_{t}\left(\varepsilon^{\prime}\right) \Delta a-\varepsilon^{\prime}
$$

incentive compatibility requires $\Delta a \geq \lambda \Delta Y_{t}$. Given concavity of the investor's payoff $b_{t}(a)$, it is optimal to make this constraint bind, so that $\Delta a=\lambda \Delta Y_{t}$. This is equivalent to optimization for the cash flow diversion model in Proposition 3 with stealing rate $\lambda$. 


\section{References}

Albuquerque, R., and H. A. Hopenhayn. 2004. Optimal Lending Contracts and Firm Dynamics. Review of Economic Studies 71:285-315.

Allen, F. 1983. Credit Rationing and Payment Incentives. Review of Economic Studies 50:639-46.

Atkeson, A. 1991. International Lending with Moral Hazard and Risk of Repudiation. Econometrica 59:1069-89.

Biais, B., T. Mariotti, G. Plantin, and J-C. Rochet. 2007. Dynamic Security Design: Convergence to Continuous Time and Asset Pricing Implications. Review of Economic Studies 74:345-90.

Bolton, P., and D. Scharfstein. 1990. A Theory of Predation Based on Agency Problems in Financial Contracting. American Economic Review 80:94-106.

Bulow, J., and K. Rogoff. 1989. A Constant Recontracting Model of Sovereign Debt. Journal of Political Economy 97:155-78.

Clementi, G. L., and H. A. Hopenhayn. 2006. A Theory of Financing Constraints and Firm Dynamics. Quarterly Journal of Economics 121:229-65.

DeMarzo, P. M., and M. J. Fishman. 2007. Agency and Optimal Investment Dynamics. Review of Financial Studies 20:151-88.

DeMarzo, P. M., and Y. Sannikov. 2006. Optimal Security Design and Dynamic Capital Structure in a Continuous-Time Agency Model. Journal of Finance 61:2681-724.

Diamond, D. W. 1984. Financial Intermediation and Delegated Monitoring. Review of Economic Studies $51: 393-414$.

Fluck, Z. 1998. Optimal Financial Contracting: Debt versus Outside Equity. Review of Financial Studies $11: 383-418$.

Green, E. 1987. Lending and the Smoothing of Uninsurable Income, in E. Prescott, and N. Wallace (eds), Contractual Arrangements for Intertemporal Trade. Minneapolis: University of Minnesota Press.

Gromb, D. 1999. Renegotiation in Debt Contracts, working paper, MIT.

Harris, M., and A. Raviv. 1995. The Role of Games in Security Design. Review of Financial Studies $8: 327-67$

Hart, O. 1995. Firms, Contracts, and Financial Structure. Oxford: Oxford University Press.

Hart, O., and J. Moore. 1998. Default and Renegotiation: A Dynamic Model of Debt. Quarterly Journal of Economics 113:1-41.

Hart, O., and J. Tirole. 1988. Contract Renegotiation and Coasian Dynamics. Review of Economic Studies 55:509-40.

Jensen, M. C., and W. H. Meckling. 1976. Theory of the Firm: Managerial Behavior, Agency Costs and Ownership Structure. Journal of Financial Economics 4:305-60.

Mookherjee, D., and I. P. L. Png. 1989. Optimal Auditing, Insurance, and Redistribution. Quarterly Journal of Economics 104:399-415.

Myers, S. C. 2000. Outside Equity. Journal of Finance 55:1005-37.

Povel, P., and M. Raith. 2004. Optimal Debt with Unobservable Investments. RAND Journal of Economics 35:599-616.

Quadrini, V. 2004. Investment and Liquidation in Renegotiation-Proof Contracts with Moral Hazard. Journal of Monetary Economics 51:713-51.

Shim, I. 2006. Dynamic Prudential Regulation: Is Prompt Corrective Action Optimal? Unpublished manuscript.

Spear, S., and S. Srivastava. 1987. On Repeated Moral Hazard with Discounting. Review of Economic Studies 54:599-617. 
Spear, S., and C. Wang. 2005. When to Fire a CEO: Optimal Termination in Dynamic Contracts. Journal of Economic Theory 120:239-56.

Tchistyi, A. 2006. Security Design with Correlated Hidden Cash Flows: The Optimality of Performance Pricing. Unpublished manuscript.

Townsend, R. 1979. Optimal Contracts and Competitive Markets with Costly State Verification. Journal of Economic Theory 22:265-93.

Wang, C. 2005. Dynamic Costly State Verification. Economic Theory 25:887-916. 